\title{
Investigation of Gas Seeding for Planar Laser-Induced Fluorescence in Hypersonic Boundary Layers
}

\author{
C. J. Arisman* and C. T. Johansen \\ University of Calgary, Calgary, Alberta T2N 1N4, Canada \\ and \\ B. F. Bathel $\$$ and P. M. Danehy $\underline{\S}$ \\ NASA Langley Research Center, Hampton, Virginia 23681-2199
}

DOI: $\underline{10.2514 / 1 . J 053892}$

\begin{abstract}
Numerical simulations of the gas-seeding strategies required for planar laser-induced fluorescence in a Mach 10 (approximately Mach 8.2 postshock) airflow were performed. The work was performed to understand and quantify the adverse effects associated with gas seeding and to assess various types of seed gas that could potentially be used in future experiments. In prior experiments, NO and NO2 were injected through a slot near the leading edge of a flatplate wedge model used in NASA Langley Research Center's 31 in. Mach 10 air tunnel facility. In this paper, nitric oxide, krypton, and iodine gases were simulated at various injection rates. Simulations showing the deflection of the velocity boundary layer for each of the cases are presented. Streamwise distributions of velocity and concentration boundary-layer thicknesses, as well as vertical distributions of velocity, temperature, and mass distributions, are presented for each of the cases. A comparison between simulated streamwise velocity profiles and experimentally obtained molecular tagging velocimetry profiles using a nitric oxide seeding strategy is performed to verify the influence of such a strategy on the boundary layer. The relative merits of the different seeding strategies are discussed. The results from a custom solver based on OpenFOAM version 2.2.1 are compared against results obtained from ANSYS $®$ Fluent version 6.3.
\end{abstract}

\section{Nomenclature}

$c_{p}=$ specific heat at constant pressure, $\mathrm{kJ} / \mathrm{kg} / \mathrm{K}$

$D_{i, j} \quad=$ binary diffusion coefficient, $\mathrm{m}^{2} / \mathrm{s}$

$D_{i, m}=$ diffusion coefficient of species $i$ into the mixture, $\mathrm{m}^{2} / \mathrm{s}$

$h_{i}=$ sensible enthalpy of species $i, \mathrm{~kJ} / \mathrm{kg}$

$h_{s} \quad=$ sensible enthalpy, $\mathrm{kJ} / \mathrm{kg}$

$I=$ identity matrix

$J_{i}=$ diffusion flux of species $i, \mathrm{~kg} / \mathrm{m}^{2} / \mathrm{s}$

$K n=$ Knudsen number

$k=$ thermal conductivity, $\mathrm{W} / \mathrm{m} / \mathrm{K}$

$M a=$ Mach number

$M_{i}=$ molar mass of species $i, \mathrm{~kg} / \mathrm{kmol}$

$P=$ pressure, $\mathrm{Pa}$

$P_{\text {inf }}=$ freestream pressure, $\mathrm{Pa}$

$P_{\text {stag }}=$ stagnation pressure, $\mathrm{Pa}$

$P_{w}=$ wall pressure, $\mathrm{Pa}$

$R=$ ideal gas constant, $\mathrm{J} / \mathrm{K} / \mathrm{mol}$

$R e=$ Reynolds number

$R_{i} \quad=\quad$ mass source of species $i$

$S_{h}=$ enthalpy source, $\mathrm{kJ} / \mathrm{s} / \mathrm{m}^{3}$

$T=$ temperature, $\mathrm{K}$

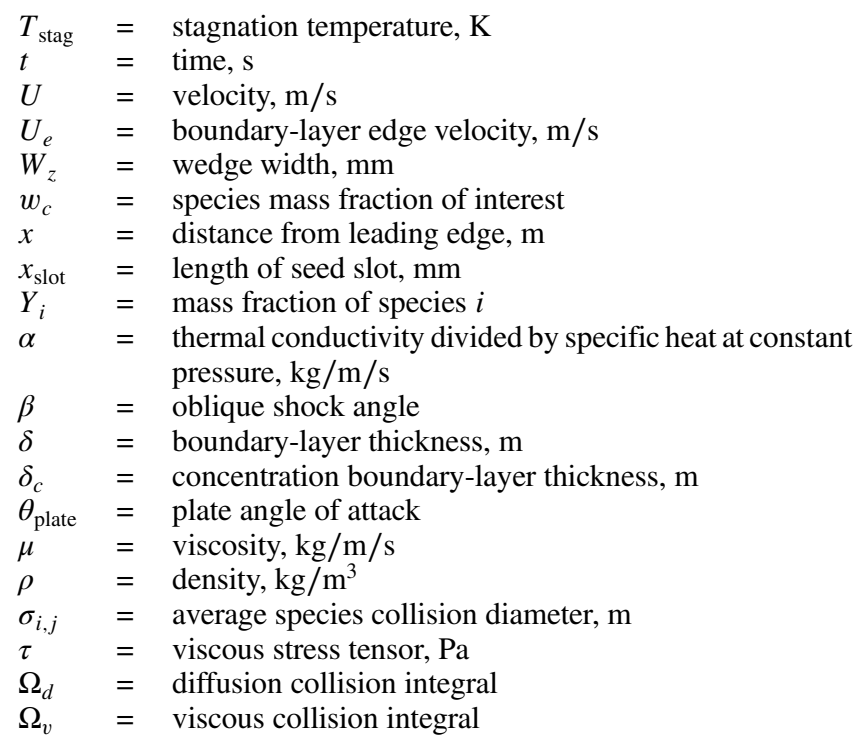

Presented as Paper 2012-1057 at the 50th AIAA Aerospace Sciences Meeting Including the New Horizons Forum and Aerospace Exposition, Nashville, TN, 9-12 January 2012; received 2 November 2014; revision received 24 February 2015; accepted for publication 4 April 2015; published online 22 July 2015 . Copyright (C) 2015 by University of Calgary and the U.S.A, as represented by the Administrator of the National Aeronautics and Space and Administration. All rights reserved. Published by the American Institute of Aeronautics and Astronautics, Inc., with permission. Copies of this paper may be made for personal or internal use, on condition that the copier pay the $\$ 10.00$ per-copy fee to the Copyright Clearance Center, Inc., 222 Rosewood Drive, Danvers, MA 01923; include the code 1533-385X/15 and $\$ 10.00$ in correspondence with the CCC.

*Graduate Student, Department of Mechanical and Manufacturing Engineering. Member AIAA.

Assistant Professor, Department of Mechanical and Manufacturing Engineering. Member AIAA.

${ }^{\ddagger}$ Research Scientist, Advanced Sensing and Optical Measurement Branch, MS 493. Member AIAA.

${ }^{\S}$ Research Scientist, Advanced Sensing and Optical Measurement Branch, MS 493. Associate Fellow AIAA.

\section{Introduction}

$\mathbf{T}$ HE tracking of a tracer species is a common method to facilitate flow visualization and to obtain quantitative measurements of flow variables. The tracer follows the flow and can then be imaged, revealing flow structures for further analysis. Tracers vary between techniques; techniques like planar laser-induced fluorescence (PLIF) [1] use a gas species capable of fluorescence excitation that has the ability to follow the flowfield and can provide quantitative velocity, temperature, and concentration measurements in addition to flow visualization. In some experimental setups, the tracer species occurs naturally in the flow. A good example of this is in combustion flows where the hydroxyl radical $\mathrm{OH}$ is present. In high-enthalpy facilities that use air as the test gas, tracer species such as nitric oxide (NO) form at high temperatures and can be uniformly distributed when flowed into the test section. However, in many situations, a seed gas is required. Examples of when seeding is required for PLIF flow visualization include the study of fuel-air mixing for supersonic combustion ramjet engines [2] and the study of reaction control 
Table 1 Experimental wind-tunnel model details

\begin{tabular}{lc}
\hline \hline Model parameter & Attribute \\
\hline Model surface material & Stainless steel \\
Model surface $\left(L_{x} \times W_{z}\right)$ & $162.5 \times 127.5 \mathrm{~mm}$ \\
Seeding slot $\left(L_{x} \times W_{z}\right)$ & $0.8 \times 11.0 \mathrm{~mm}$ \\
Location of seeding slot center $x_{\text {slot }}$ & $29.4 \mathrm{~mm}$ \\
Leading-edge radius, $r_{\mathrm{le}}$ & $0.024 \pm 0.005 \mathrm{~mm}$ \\
Plate angle & $5 \mathrm{deg}$ \\
\hline \hline
\end{tabular}

system jet interactions with hypersonic crossflows associated with planetary entry vehicles [3-ㅗㄱ.

Injecting a foreign gas into a flow has several requirements and limitations. First, when used with a nonintrusive technique, it is important that the seeded gas does not adversely affect any important features of the flow. For example, hypersonic boundary-layer stability can be very sensitive and has the potential to be altered by small flow disturbances, such as surface defects on the test model. As a result, hypersonic boundary-layer studies are particularly concerned with the way the seeding strategy alters boundary-layer stability. In addition to unwanted aerodynamic effects, local thermodynamic properties near the injected gas can be affected, which can alter dimensionless parameters important in the flow. For example, changes in the local specific-heat ratio, thermal conductivity, or viscosity could result in local changes in the Mach number, Prandtl number, or Reynolds number, respectively. If the seeded gas is a reactive species, then there is also a concern that the heat release from reactions might also distort the flowfield.

Gas seeding near the model or from the model can present challenges but often can be incorporated seamlessly into a test. If gas injection is being used anyway, for example, then gas seeding may not additionally perturb the flowfield, provided the seed gas is nonreacting and does not significantly change the thermodynamic properties of the jet. Seeding of NO into the reaction control system jets of the Orion Multi-Purpose Crew Vehicle is an example of this type of gas-seeding strategy $[3,4]$. Another example of intentional blowing is the use of jets for active control of hypersonic boundary layers [6]. If gaseous injection is not being studied, then injection through a port normal to the flow on the model surface can be used. In this case, if the ratio of the injected gas momentum to crossflow momentum is too large, then the injected gas will severely augment the crossflow and perhaps become a source of instability.

Recent PLIF measurements using a NO seeding strategy have been used to study the transition-to-turbulence process in hypersonic boundary-layer flows at the NASA Langley Research Center [7-10]. These measurements were motivated by a need to better understand the underlying physical mechanisms responsible for transition. The transition-to-turbulence process in a hypersonic boundary layer, and subsequent breakdown to turbulence, can result in significantly increased heat transfer rates to a flight vehicle's surface. This poses a potential risk to the thermal protection systems (TPSs) [11]. Better predictive methods can be developed by gaining better insight into the physical mechanisms governing the transition-to-turbulence and turbulent heat transfer processes. These methods could then be used to better select and size a TPS. This would ensure that the flight vehicle is adequately insulated while avoiding excess insulation that is associated with uncertainties in current predictive capabilities. In a 2008 review of transition to turbulence in hypersonic flows, Schneider stated that the instability mechanisms that lead to transition, which differ from the mechanisms at subsonic speeds, were still poorly understood [12]. These mechanisms include the concave-wall Görtler instability [13], the first- and second-mode Mack instabilities [14], and the three-dimensional crossflow instability $[15,16]$. Moreover, it has been shown experimentally that the presence of surface roughness or discrete protuberances on the surface can influence the transition length. Unfortunately, there is no general mechanism-based theory to determine the conditions under which roughness can cause transition [13]. Since vehicle design tools rely on computational fluid dynamics, relevant experimental data are critical for numerical model validation.

In the NASA Langley Research Center's PLIF experiments, a planar, $20 \mathrm{deg}$ wedge with a sharp leading edge $(R=$ $0.024 \pm 0.005 \mathrm{~mm}$ ) was placed into the test section and NO gas was seeded through a slot on the model to allow for PLIF images to be obtained downstream. A series of protuberance shapes with various heights were mounted on the wedge surface, and PLIF flow visualization and quantitative molecular tagging velocimetry (MTV) measurements were obtained. Figure 1 shows the wedge model and gas-seeding slot that were used during several of the experiments [17]. Table 1 provides a summary of the attributes of the model used in the NO PLLIF experiments and in the simulations presented in this paper.

Details of the $31 \mathrm{in}$. Mach 10 air blowdown facility used in the NO PLIF experiments are provided in [18]. In this facility, the stagnation pressure and model angle of attack (AOA) can be varied to produce different postshock edge conditions, including Reynolds number, on the wedge surface.

For boundary-layer transition experiments in which PLIF-based measurements with tracer gas seeding are used, a tradeoff exists between minimizing perturbation imparted to the flowfield and depositing high enough concentrations of tracer species into the region of interest to provide measureable fluorescence signals. Measurements far from the wall are desired because transition to turbulence begins near the edge of the boundary layer in hypersonic flows [19]. Also of interest is the boundary-layer edge velocity, which is often inferred from oblique shock calculations but may not be accurate due to viscous interaction effects [20]. The seed material is transported away from the wall, both by advection (if the injected gas momentum is relatively high) and by diffusion. Therefore, the rate of diffusion of the seed gas into the crossflow gas is important, since it affects concentration levels downstream of the injection location in applications where perturbing the flow is undesirable. An analytic expression describing the growth of a concentration boundary layer relative to the growth of an incompressible velocity boundary layer

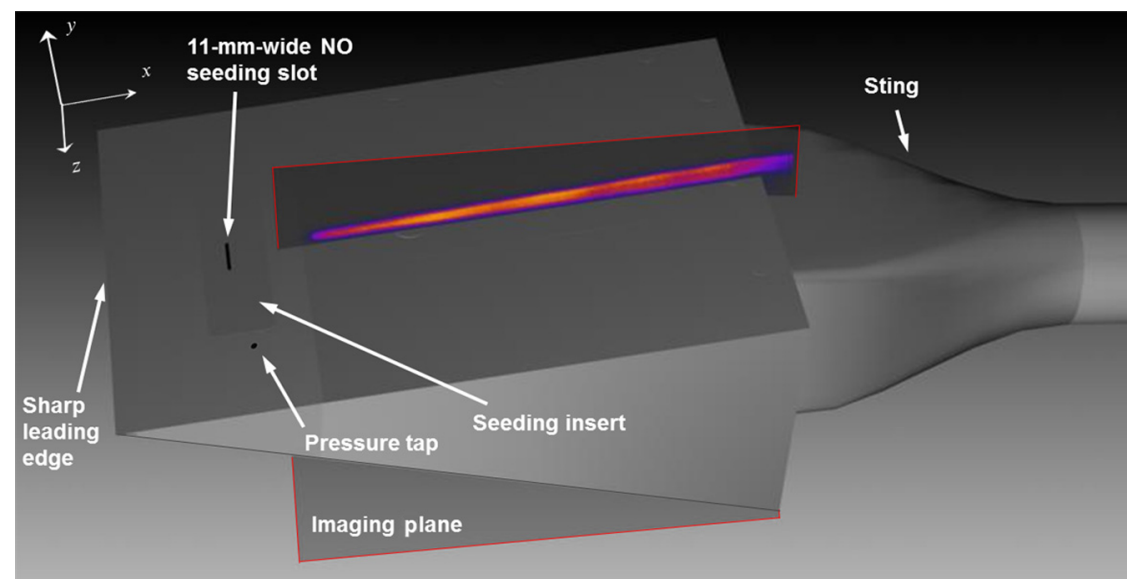

Fig. 1 Schematic of wedge model, indicating the gas-seeding slot. Reproduced from [17] 


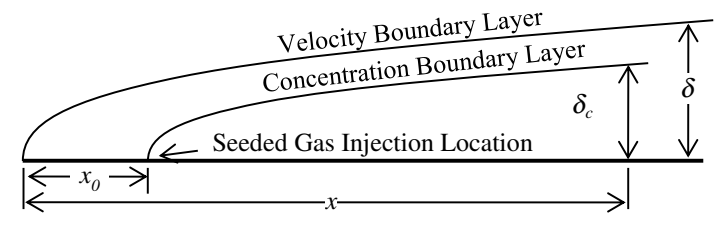

Fig. 2 Schematic of growth of the velocity and concentration boundary layers on a flat plate. Adapted from [21].

on a two-dimensional flat plate is useful in understanding this process [21]. The ratio of the concentration to velocity boundary-layer thickness, $\delta_{c} / \delta$, for incompressible flow is defined as

$$
\frac{\delta_{c}}{\delta}\left(\frac{13}{14}\right) S c^{1 / 3}\left(1-\left(\frac{x_{0}}{x}\right)^{3 / 4}\right)^{1 / 3}
$$

where $x$ and $x_{0}$ are the distance from the plate leading edge and the gas-seeding location relative to the leading edge, respectively. The equation is, of course, only valid for $x$ greater than $x_{0}$. These parameters are illustrated in Fig. 2. In this expression, it is assumed that the velocity of the seeded gas is negligible compared to freestream flow. In addition, it is assumed that the flow is laminar, incompressible, and steady. The Schmidt number $S c$, which is the ratio of viscous diffusion to mass diffusion, is defined as

$$
S c=\frac{\mu}{\rho D}
$$

where $\mu, \rho$, and $D$ are the dynamic viscosity, gas density, and diffusion coefficient, respectively. Seeded gases with relatively low Schmidt numbers experience fast rates of mass diffusion, allowing the concentration layer to penetrate and extend past the velocity boundary layer. In contrast, seeded gas with a large Schmidt number will remain concentrated closer to the plate surface. The position of the injection location relative to the plate leading edge $x_{0}$ is also important, since the velocity boundary layer has a finite thickness at the injection location. Although Eq. (1) is based on incompressible flow assumptions and constant distribution of the Schmidt number, the expression is still useful for illustrating trends on the diffusion of different seed gases.

The objectives of this study are to 1) identify and further understand adverse fluid dynamic effects of seeding various pure gases from a slot into a laminar hypersonic boundary layer, 2) determine how far from the wall different seed gases penetrate into the hypersonic boundary layer, and 3) compare the relative merits of the different seed gases in terms of perturbations to the flow and the spatial range of coverage provided. In this work, it is assumed that the purpose of the gas seeding is to allow qualitative and quantitative PLIF measurements to be performed. Using computational fluid dynamics, three different seed gases of $\mathrm{NO}$, krypton $(\mathrm{Kr})$, and iodine $\left(I_{2}\right)$ have been simulated. These seed gases have been selected, as they are typically used for hypersonic flow visualization or quantitative measurement purposes using the PLIF technique. Table 2 provides a brief summary of each seed gas considered [22].

Although the current study focuses on gas seeding from a perspective of flow visualization, the results presented are valuable to other fields of study. Gas seeding into hypersonic boundary layers is useful in a variety of other applications. Examples include reducing turbulent skin friction through the combustion of boundary-layer hydrogen $[23,24]$ and inhibiting the transition to turbulence through the injection of carbon dioxide $\left(\mathrm{CO}_{2}\right)$ into hypersonic boundary layers [25].

\section{CFD Solvers}

\section{A. Summary of CFD Solvers}

Several seeding flow rates have been simulated using ANSYS Fluent version 6.3 and OpenFOAM version 2.2.1 to observe the levels of perturbation of the velocity boundary layer and to understand any adverse effects that seeding has on the PLIF measurements. The simulations have been performed in two CFD packages in order to gain further confidence in the results and minimize errors associated with modeling and computation. The effects of chemical reactions, wedge AOAs, and facility stagnation pressure on the flow are not considered in this study. Instead, special attention is given to the rates of gas diffusion and the growth of the concentration boundary layer relative to the velocity boundary layer for each respective gas.

The density-based implicit solver was used in ANSYS Fluent, which simultaneously solves the compressible continuity, momentum, energy, and species transport equations as a coupled set. The OpenFOAM solutions were obtained using a modified version of the rhoCentralFoam solver which solves the same equations as ANSYS Fluent but with a semi-implicit segregated method.

The rhoCentralFoam and ANSYS Fluent codes solve the NavierStokes (continuum) governing equations. The freestream Knudsen number, which is the ratio of the mean free path to a characteristic length scale, is estimated to be approximately $K n=0.003$ in NASA's 31 in. Mach 10 facility $\left(P_{\text {stag }}=350 \mathrm{psi}, 2.41 \mathrm{Mpa}\right.$; length scale based on plate length). Therefore, the flow is not considered to be rarefied $(K n<0.01)$ and a direct simulation Monte Carlo (DSMC) solver is not required. DSMC simulations calculate the collisions between particles in a probabilistic manner and are typically very computationally expensive.

Compared to the other Navier-Stokes solvers, rhoCentralFoam and ANSYS Fluent include the dissipation function in the energy equation, which is required to predict viscous heating near wall boundaries. The solvers also accurately capture flow discontinuities (e.g., shock waves) through the use of a central-upwind finite volume discretization scheme [26] for rhoCentralFoam and the Roe fluxdifference splitting (Roe-FDS) scheme [27] for ANSYS Fluent. The rhoCentralFoam central-upwind scheme is based on the work by Nessyahu and Tadmor [28] but is semidiscrete and nonstaggered, such that it can operate with collocated meshes as developed by Kurganov and Tadmor [29]. This type of scheme was developed because solution variables, such as velocity and pressure, are often collocated in popular CFD software packages, including ANSYS Fluent and OpenFOAM.

The advantage of the central-upwind and Roe-FDS schemes over other schemes is that they can produce nonoscillatory solutions near flow discontinuities. Examples of other numerical schemes that can accurately treat flow discontinuities include the monotone upstreamcentered schemes for conservation laws [30], the piecewise parabolic method [31], essentially nonoscillatory (ENO) schemes [32], weighted $\overline{\mathrm{ENO}}$ schemes [33], and the Runge-Kutta discontinuous Galerkin method [34]. None of these schemes are included in the standard OpenFOAM or ANSYS Fluent packages.

A detailed description of rhoCentralFoam can be found in [26], where rhoCentralFoam has been used to solve supersonic flow over a

Table 2 Properties of seed gases at wall conditions of $P=236 \mathrm{~Pa}, T=314 \mathrm{~K}$, and $x=$ $75.4 \mathrm{~mm}$

\begin{tabular}{lccc}
\hline \hline Property & $\mathrm{NO}$ & $\mathrm{Kr}$ & $\mathrm{I}_{2}$ \\
\hline Molecular weight $\mathrm{MW}, \mathrm{kg} / \mathrm{kmol}$ & 30.01 & 83.80 & 253.8 \\
Collision diameter $\sigma$ [22], $\mathrm{m}^{2}$ & 3.49 & 3.65 & 5.16 \\
Lennard-Jones parameter [22] & 116.7 & 178.9 & 474.2 \\
Binary diffusion coefficient $D, \mathrm{~m}^{2} / \mathrm{s}$ & $9.69 \mathrm{e}-3$ & $7.18 \mathrm{e}-3$ & $3.82 \mathrm{e}-3$ \\
Schmidt number & 0.76 & 0.98 & 1.59 \\
$R e_{\text {jet }}$ & 185 & 140 & 255 \\
Hazards & Reactive with air & Nontoxic asphyxiant & Reactive with water \\
\hline \hline
\end{tabular}


forward facing step, supersonic jet, and shock tube [26]. The rhoCentralFoam solver in its standard form does not include the capability to simulate species transport or include chemical reactions. A modified version has been used to solve radiation associated with hypersonic flows around reentry vehicles [35]. A similar compressible OpenFOAM solver developed by Chapuis et al. has been used to simulate supersonic combustion and gaseous explosions [36]. In the current work, the rhoCentralFoam solver was modified to account for species transport.

\section{B. Governing Equations}

The standard rhoCentralFoam solver has been modified to create the rhoCentralBinaryFoam solver. In its standard form, rhoCentralFoam solves the unsteady, compressible Navier-Stokes equations for both laminar and turbulent flows. Whereas the standard rhoCentralFoam solver computes the transport of total energy, the modified version solves the sensible enthalpy equation [Eq. (5)] in order to easily include the chemical reaction and species transport terms from the reactingFoam solver [37]. The conservation of mass, momentum (neglecting body forces), and energy used by the rhoCentralBinaryFoam and ANSYS Fluent solvers are defined as

$$
\begin{gathered}
\frac{\partial \rho}{\partial t}+\nabla \cdot(\rho u)=0 \\
\frac{\partial(\rho u)}{\partial t}+\nabla \cdot\left(\rho u^{2}\right)=\nabla P+\nabla \cdot \tau \\
\frac{\partial\left(\rho h_{s}\right)}{\partial t}+\nabla \cdot\left(\rho u h_{s}\right)-\frac{\mathrm{D} P}{\mathrm{D} t}=\nabla \cdot\left[\alpha \nabla h_{s}+\sum_{i=1}^{n} h_{i} J_{i}\right] \\
+\nabla \cdot(\tau \cdot u)+S_{h}
\end{gathered}
$$

where $\rho, u, P, h_{s}, T$, and $S_{h}$ are the gas density, velocity, pressure, sensible enthalpy, temperature, and enthalpy source, respectively; and $\alpha$ is defined as $k / c_{p}$, where $k$ is the thermal conductivity and $c_{p}$ is the specific heat at constant pressure. The viscous stress tensor $\boldsymbol{\tau}$ in vector form is defined as

$$
\tau=\mu\left(\nabla u+(\nabla u)^{T}-\frac{2}{3} \nabla \cdot u I\right)
$$

where $\mu$ is the viscosity, and $I$ is the unit tensor. The viscous stress tensor is $2 \mu$ multiplied by the deviatoric component of the deformation gradient tensor. It is worth noting that the left-hand side of the ANSYS Fluent energy equation is written in terms of total energy $E$ given by

$$
E=h-\frac{p}{\rho}+\frac{u^{2}}{2}
$$

The enthalpy transport term

$$
\sum_{i=1}^{n} h_{i} J_{i}
$$

has been included in the energy equations, which allows for variable Prandtl, Schmidt, and Lewis numbers. In the standard reactingFoam solver, these variables are treated as a constant with the Lewis number assumed to be equal to one. The thermal conductivity is calculated from a modified Euken correction equation taken from the work of Hollis [38]:

$$
k=\mu\left(\frac{15}{4}-1.32\left(\frac{c_{p}}{R}-\frac{5}{2}\right)\right) R
$$

Specific-heat values for $\mathrm{NO}, \mathrm{I}_{2}$, and $\mathrm{Kr}$ were taken from the National Institute of Standards and Technology/Joint-Army-NavyAir Force tables [39]. The viscosity is calculated based on kinetic theory from the Chapman-Cowling relationship, which is also found in the work of Hollis [38]:

$$
\mu=2.6693 * 10^{6} \frac{\sqrt{M T}}{\sigma \Omega_{v}}
$$

Because the rhoCentralFoam solver is limited to single-species nonreacting flows in its standard form, modifications were implemented to expand its capability and solve this hypersonic flow with a binary gas mixture. To use it to investigate gas seeding, binary species transport and binary diffusion coefficient modeling were added. Implementation of these features in rhoCentralBinaryFoam is based on the structure of the available solver reactingFoam [37]. The transport of multiple species mass fraction $Y_{i}$ for both solvers, neglecting thermal diffusion, is given by the following conservation equation:

$$
\frac{\partial\left(\rho Y_{i}\right)}{\partial}+\nabla \cdot\left(\rho u Y_{i}\right)=-\nabla \cdot J_{i}+R_{i}
$$

where $J_{i}$ is the diffusion flux of species $i$ and is defined as

$$
J_{i}=-\rho D_{i, m} \nabla Y_{i}
$$

The standard reactingFOAM solver assumes a unity Schmidt number in the species conservation equation. Since a variable Schmidt number is required for the current simulation, a binary species diffusion coefficient has been included in the species conservation equation. For both solvers, the binary diffusion coefficient $D_{i, m}$ for species $i$ in the mixture is determined from the Chapman-Enskog equation $[\underline{40}, \underline{41}]$ :

$$
D_{i, m}=0.00188 \frac{\left[T^{3}\left(1 / M_{a}+1 / M_{b}\right)\right]^{1 / 2}}{P \sigma_{a b}^{2} \Omega_{d}}
$$

where $\sigma_{a b}$ is the average species collision diameter based on tabulated values published by Svehla [22], and $\Omega_{d}$ is the diffusion collision integral. For the diffusion coefficient calculation, $P$ is in bar. $M_{a}$ and $M_{b}$ are the molecular weights of species $a$ and $b$, respectively. All mixture properties are calculated based on a mass-weighted average of the individual species properties.

The rhoCentralBinaryFoam solver handles viscous effects by first solving the inviscid equation and using the inviscid solution as a predictor for the viscous solution, correcting for the diffusive terms [26]. The solver is unsteady, and steady-state solutions are obtained by marching forward in time until fluctuations in flow variables no longer subsist [26]. Since the Reynolds number of the flow, based on the freestream velocity and plate length, is small $\left(R e=3.4 \times 10^{5}\right)$, turbulence modeling is not required in the simulations. However, rhoCentralFoam and ANSYS Fluent do have the ability to use builtin Reynolds-averaged Navier-Stokes and large-eddy simulation turbulence models for higher-Reynolds-number flows. In addition, ANSYS Fluent also has the ability use an embedded large-eddy simulation model.

\section{Numerical Setup}

The computational domain is based on the wedge model used in the experiments performed in NASA Langley Research Center's 31 in. Mach 10 facility [7-9,42,43]. Figure 3 shows a schematic of the wind tunnel facility. Seen in the figure is the testion; the viewing section is shown on the left-hand side of the figure with the camera setup. The laser system can be seen on the right of the facility.

A schematic of the computational domain relative to the wedge model and sting is shown in Fig. 4. The domain is two-dimensional, $200 \mathrm{~mm}$ in length ( $x$ direction), and $30 \mathrm{~mm}$ in height ( $y$ direction). The origin of the coordinate system is at the leading edge of the 


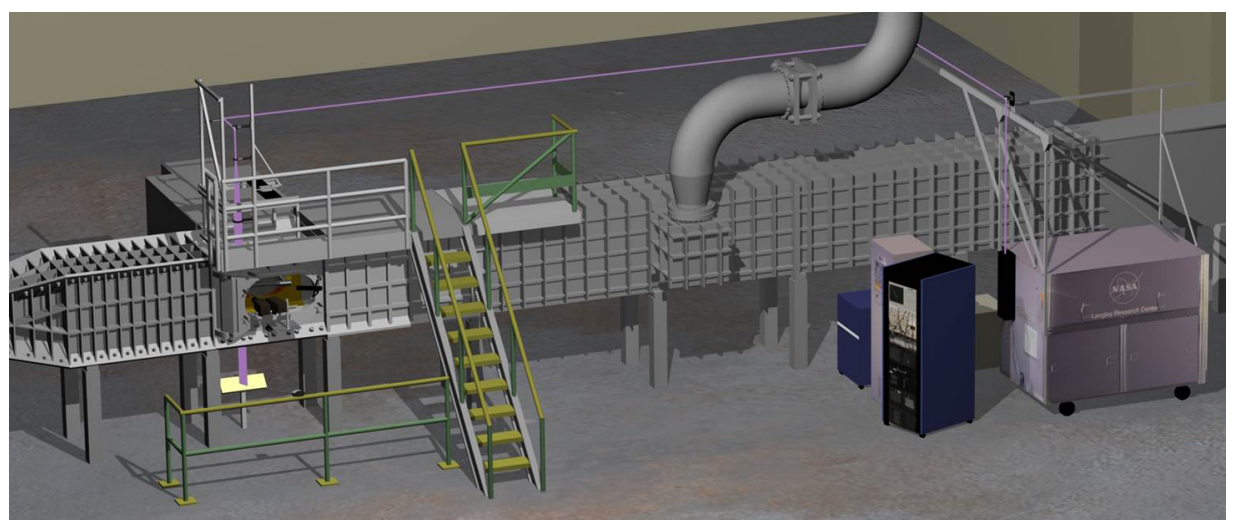

Fig. 3 NASA Langley Research Center's 31 in. Mach 10 air tunnel facility with PLIF systems. Reproduced from []].

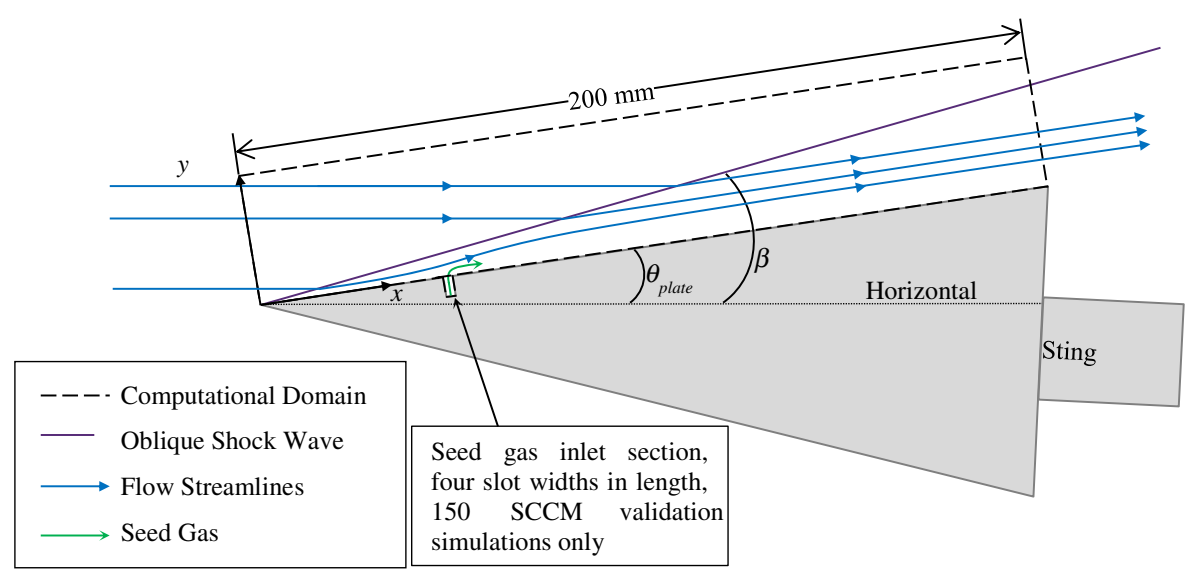

Fig. 4 Computational domain.

wedge. The gas is seeded from a slot that is $0.81 \mathrm{~mm}$ wide and $11 \mathrm{~mm}$ deep, located $29.4 \mathrm{~mm}$ downstream of the leading edge. An inlet section for the seed gas was included in the computational domain for the rhoCentralBinaryFoam 150 standard cubic centimeters per minute (SCCM) validation simulations. The depth of the seed slot was equal to four seed slot widths and was required due to boundary condition constraints in the OpenFOAM toolkit.

The bottom of the domain is aligned with the top surface of the wedge. Changes in plate angle $\theta_{\text {plate }}$ are controlled by specifying the inlet velocity (direction) on the top and left boundaries. Constant pressure, temperature, and velocity values of $P=68.4 \mathrm{~Pa}$, $T=52.3 \mathrm{~K}$, and $U=1407.3 \mathrm{~m} / \mathrm{s}(M a=9.7)$ are specified at the inlet boundaries. These freestream values were calculated from the facility stagnation pressure $\left(P_{\text {stag }}=350 \mathrm{psi}, 2.41 \mathrm{MPa}\right)$ and temperature $\left(T_{\text {stag }}=1000 \mathrm{~K}\right)$ values specified in one of the representative tests. Equations relating the stagnation conditions to the freestream values are outlined in the literature [38]. In the simulations, the wedge was oriented at an angle of $\theta_{\text {plate }}=5 \mathrm{deg}$. The bottom wall was specified as a no-slip condition, zero normal gradient in pressure, and with fixed temperature $(T=314 \mathrm{~K})$. The fixed temperature was determined from the experimental data at this condition. The right outflow boundary was specified as a zero normal gradient for the temperature, velocity, and pressure boundary conditions. There was a concern that the zero gradient pressure boundary condition would result in unwanted wave reflections at the outlet. After running the simulation, it was found that, as long as the oblique shock wave exits on the right boundary rather than the top boundary, no reflections were observed.

The walls of the seed gas inlet section were modeled as slip boundaries and given a constant static temperature of $314 \mathrm{~K}$. The total temperature of the pipe inflow boundary was calculated based on the desired mass flow rate and the pressure at the jet outlet. Three seed gas mass flow rates were simulated: 1) jet off with no seed gas entering the domain; 2) jet off with seed gas allowed to enter through diffusive flux; and 3) jet on with a seed gas mass flow rate of $\dot{m}=3 \mathrm{mg} / \mathrm{s}$, which is equivalent to 150 standard cubic centimeters per minute. This is typical for NO PLIF in NASA Langley Research Center's 31 in. Mach 10 air tunnel facility.

Simulation results corresponding to the rhoCentralBinaryFoam and ANSYS Fluent solvers were compared for both cases.

\section{Sensitivity Results}

\section{A. Mesh Sensitivity}

Figure $\underline{5}$ shows the computational grid near the leading edge and the jet inflow boundary for the ANSYS Fluent version 6.3 simulations. The base grid concentrates the nodes near the leading edge in both the streamwise and vertical directions, with a resolution of approximately 20 nodes $/ \mathrm{mm}$. Dynamic mesh refinement is used near the wall surface to ensure that the wall $y+$ is less than unity along the entire wall surface. Approximately 16 nodes of the base mesh are distributed across the jet diameter. Near the wall surface, the number of nodes across the jet surface increases to approximately 128 . In the entire computational domain, there are approximately 417,000 nodes. A grid sensitivity analysis showed that an increase in grid size to 1.6 million nodes had no effect on distributions of velocity, mass, or temperature.

Initial simulations using the rhoCentralBinaryFoam solver used a cell size, $\Delta=0.1 \mathrm{~mm}$, in the vertical direction, which were measured at the approximate center of the boundary layer. This proved to be inadequate to properly resolve the boundary layer. The difference in predictions between simulations with grid spacing of 0.05 and $0.03 \mathrm{~mm}$ is negligible (less than $0.1 \%$ ). Therefore, the solution is independent of grid size when the spacing is smaller than $0.05 \mathrm{~mm}$. The maximum Courant number was limited to 0.3 in the simulations. The simulation results were insensitive to the time step when the Courant number was below this value. 


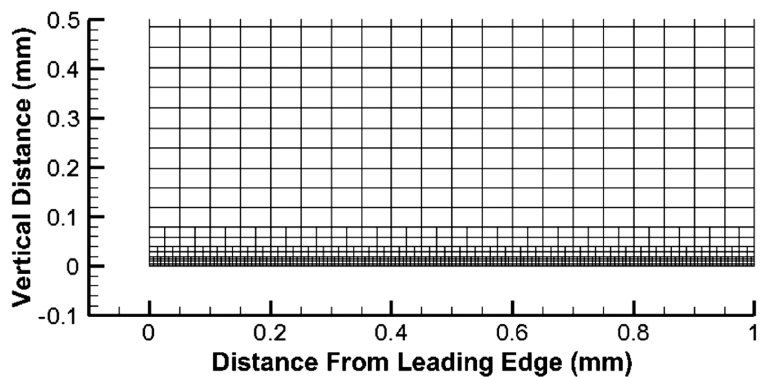

a)

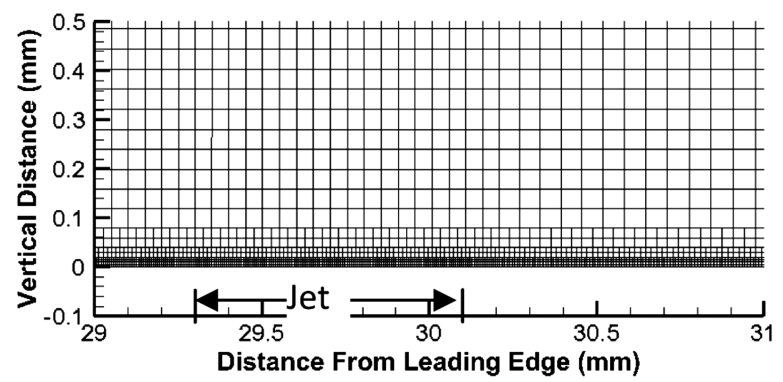

b)

Fig. 5 Computational grid near leading edge (left) and at gas-seeding location (right): ANSYS Fluent version 6.3 CFD solver.
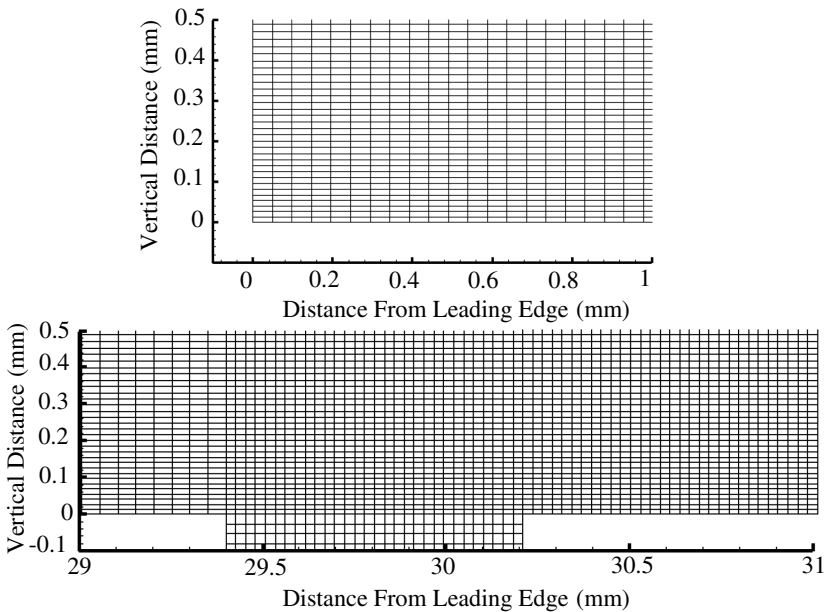

Fig. 6 Computational grid near leading edge (top) and at gas-seeding location (bottom): rhoCentralBinaryFoam solver.

Figure $\underline{6}$ shows the resulting rhoCentralBinaryFoam mesh, which consists of approximately 1.2 million nodes. This mesh has considerably more nodes than the ANSYS Fluent version 6.3 mesh. However, it is believed that the mesh is overrefined due to mesh generation constraints in the OpenFOAM toolkit. The rhoCentralBinaryFoam mesh was not dynamically refined and, as a result, more nodes are needed to attain resolution at the wall similar to the ANSYS Fluent version 6.3 simulations. Dynamic refinement libraries are present for meshes in OpenFOAM; however, this has not yet been implemented for the rhoCentralBinaryFoam code.

\section{B. Numerical Schemes}

Greenshields et al. recommended that a limited van Leer interpolation scheme be used when using rhoCentralFoam [26]. However, it was found that the use of the van Leer limiter resuleds in an oscillatory solution for the cases analyzed. These oscillations did not decay as the simulation time increased. Therefore, a Gamma differencing scheme was used instead, as it maintained steep gradients near the shock but dampened oscillations [44].

\section{Comparison of CFD Solutions}

Simulation results from rhoCentralBinaryFoam are compared directly against the ANSYS Fluent version 6.3 results. Figure 7 shows contours of the Mach number over the computational domain for the simulation with no gas seeding. The major flow features of note are the boundary layer and oblique shock wave that form in the flow.

Figure 8 shows comparisons of vertical distributions of the Mach number and temperature for the same case with no gas seeding. Also shown in the figure are results from a compressible laminar boundary-layer (CLBL) code supported by the Virginia Polytechnic Institute and State University (hereafter referred to as Virginia Tech) [45]. The vertical $y$ distributions are displayed at a streamwise position of $x=106 \mathrm{~mm}$ downstream of the leading edge. This position corresponds to the location of a supersonic pitot rake used in the experiments.

In general, there is good agreement between the rhoCentralBinaryFoam code and ANSYS Fluent in predicting mean flow quantities. The differences between the simulated results and the CLBL code are due to the inviscid oblique shock assumption made when calculating the boundary-layer edge conditions. The OpenFOAM and Fluent results both show viscous interaction effects at the leading edge that alter the shock angle and the postshock conditions.

RhoCentralBinaryFoam's binary diffusion model was also compared to ANSYS Fluent. Both solvers computed NO, $\mathrm{I}_{2}$, and $\mathrm{Kr}$ seeding into the boundary layer using the same freestream conditions. This comparison was done for both a mass flow rate of $3 \mathrm{mg} / \mathrm{s}$ and for the case where the mass flow rate was zero but mass was allowed to enter the domain via diffusive flux at the jet boundary. The comparison can be seen in Fig. 9.

Although excellent agreement between bulk flow properties is demonstrated, there are slight differences near the wall. These differences are suspected to be due to the different mass flow boundary conditions between the two codes. The Fluent simulations specify an average mass flux over the boundary where OpenFOAM

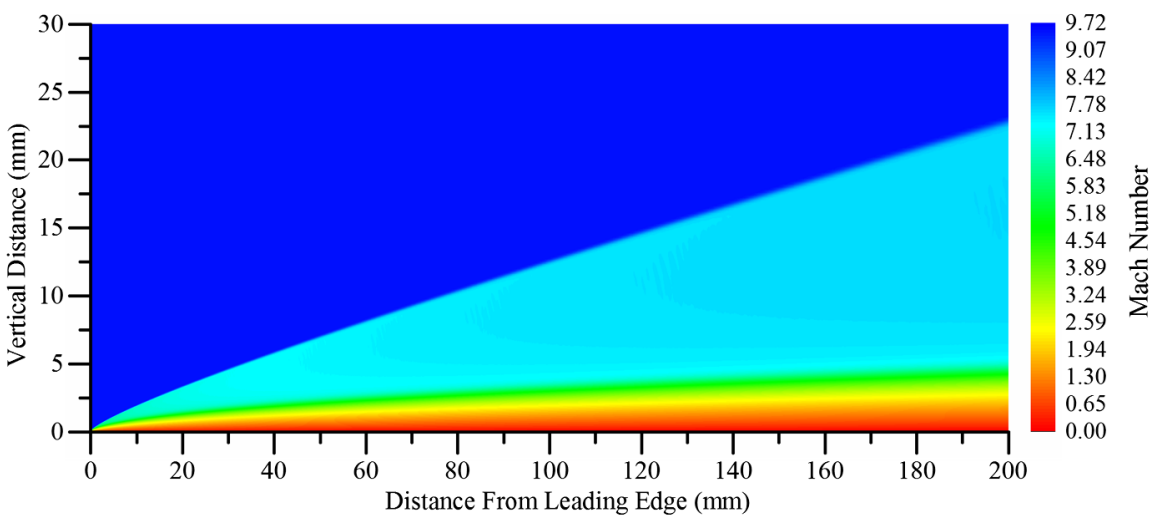

Fig. 7 Contours of Mach number predicted by rhoCentralBinaryFoam. No gas seeding. 

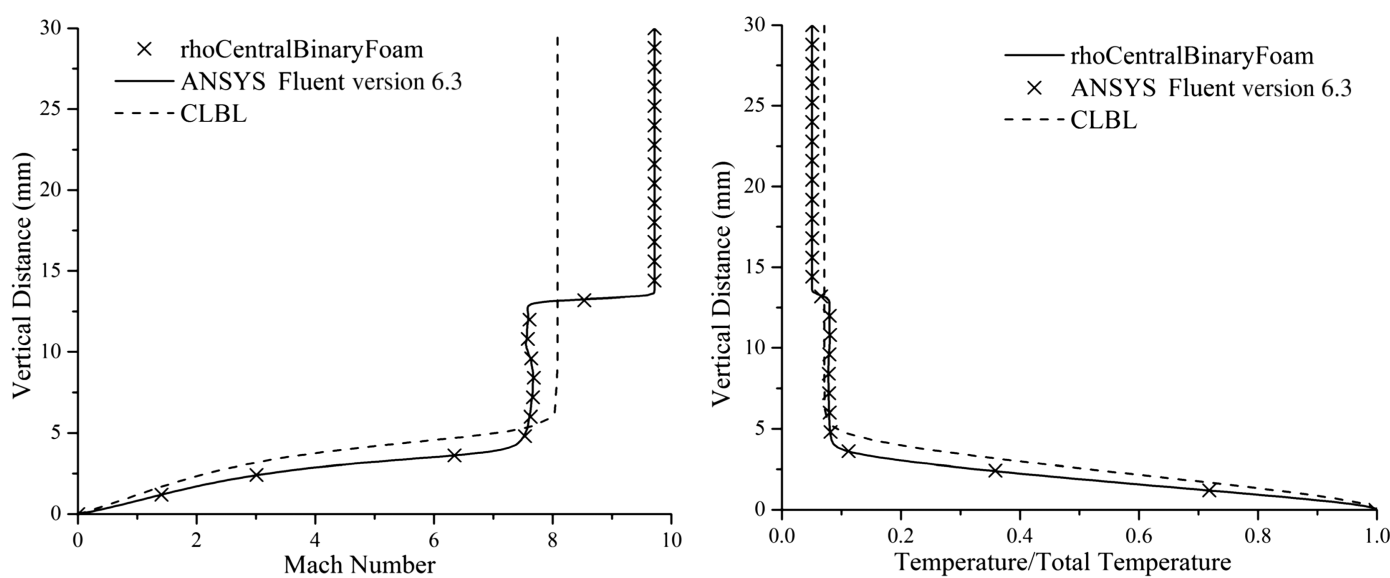

Fig. 8 Vertical distributions of Mach number (left) and temperature/total temperature (right) predicted by rhoCentralBinaryFoam, ANSYS Fluent and Virginia Tech's laminar compressible boundary-layer code. No gas seeding.
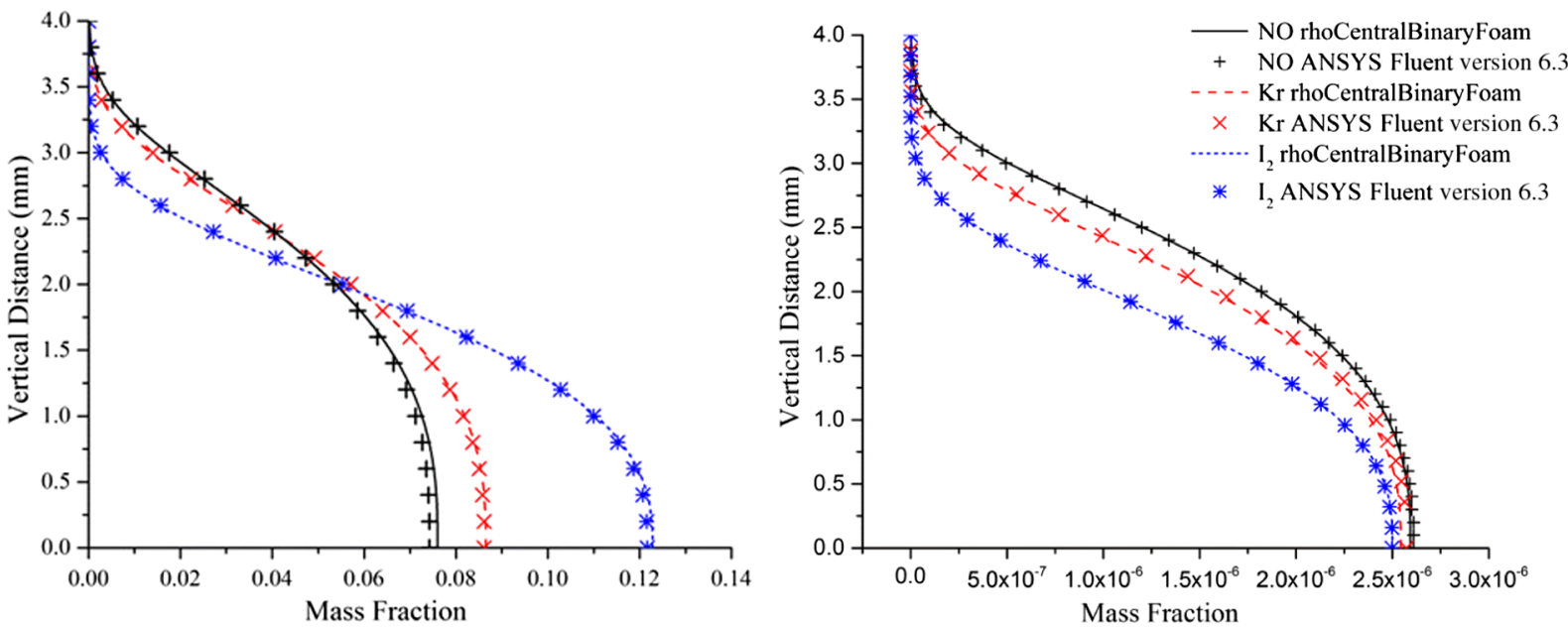

Fig. 9 Vertical distributions of NO mass fraction predicted by rhoCentralBinaryFoam and ANSYS Fluent. NO flow rate $=3 \mathrm{mg} / \mathrm{s}$ (left), and diffusive flux only (right).

specifies a mass flow rate. Slight differences between the two methods of controlling the mass flow are suspected to be responsible for the differing wall concentrations, as these differences are not present in the diffusive flux-only case. The maximum deviation between the two codes over the entire boundary is less than $5 \%$, with the maximum located at the outflow boundary. The discrepancy between the two codes has negligible impact on the simulation results outside the wall concentration and do not affect the conclusions of the study.

\section{Comparison to Experimental Results}

To assess the validity of the computation results, a comparison with experiments performed in the $31 \mathrm{in.} \mathrm{Mach} 10$ air blowdown facility using the $20 \mathrm{deg}$ wedge model was made. Comparisons were made against the rhoCentralBinaryFoam results. The first validation effort involved comparison of computed versus experimental streamwise velocity profiles. The experimental profiles were obtained using NO PLIF molecular tagging velocimetry during a single run in the wind tunnel. Details regarding the NO PLIF MTV technique can be found in [43]. The profiles extended in the wall-normal direction and were obtained at multiple streamwise locations above the wedge model surface. A nominal NO mass flow rate of $\dot{m}_{\mathrm{NO}}=3 \mathrm{mg} / \mathrm{s}$ was used to seed the boundary layer. Figure 10 shows the comparison between the computed (solid curves) and experimental (points) streamwise velocity profiles. The vertical lines correspond to the streamwise origin of each profile. Computed profiles both with (solid lines) and without (dashed lines) simulated NO seeding are presented. The centers of the horizontal data points correspond to the measured mean streamwise velocity, whereas the width corresponds to the uncertainty in the mean. For these data, a total of 183 single-shot images were acquired to calculate the experimental streamwise velocities and uncertainties. In some instances, especially near the edge of the boundary layer, low signal to noise limited the number of single-shot measurements used to calculate a mean streamwise velocity. Near the model wall, laser scatter off of the model surface prevented a useful measurement of streamwise velocity. Over the course of the run, a small physical downward displacement of the model was observed. Presumably, the displacement was a result of nonuniform mechanical and thermal loading on the sting. The plate surface was also rotated approximately $0.15 \mathrm{deg}$ with respect to the horizontal axis of the camera. To correct for the displacement and rotation, the raw images were translated upward and rotated clockwise using the MATLAB ${ }^{\circledR}$ function imwarp with cubic interpolation. The uncertainty in the wall-normal placement of the experimental data points was estimated to be $\pm 0.13 \mathrm{~mm}$.

Figure 10 shows that the best agreement with the experiment occurred for the computation with a simulated $\dot{m}_{\mathrm{NO}}=3 \mathrm{mg} / \mathrm{s}$ seed (solid curves). Relative to the computation with no seed (dashed curves), both the experimental measurements and computations with seeding exhibited a velocity deficit and increased thickness. This result was to be expected, as the seeding altered the streamwise momentum of the boundary layer.

A second validation consists of a comparison between the computed and experimental wall pressures at a point $33 \mathrm{~mm}$ downstream of the leading edge. This comparison is used to 

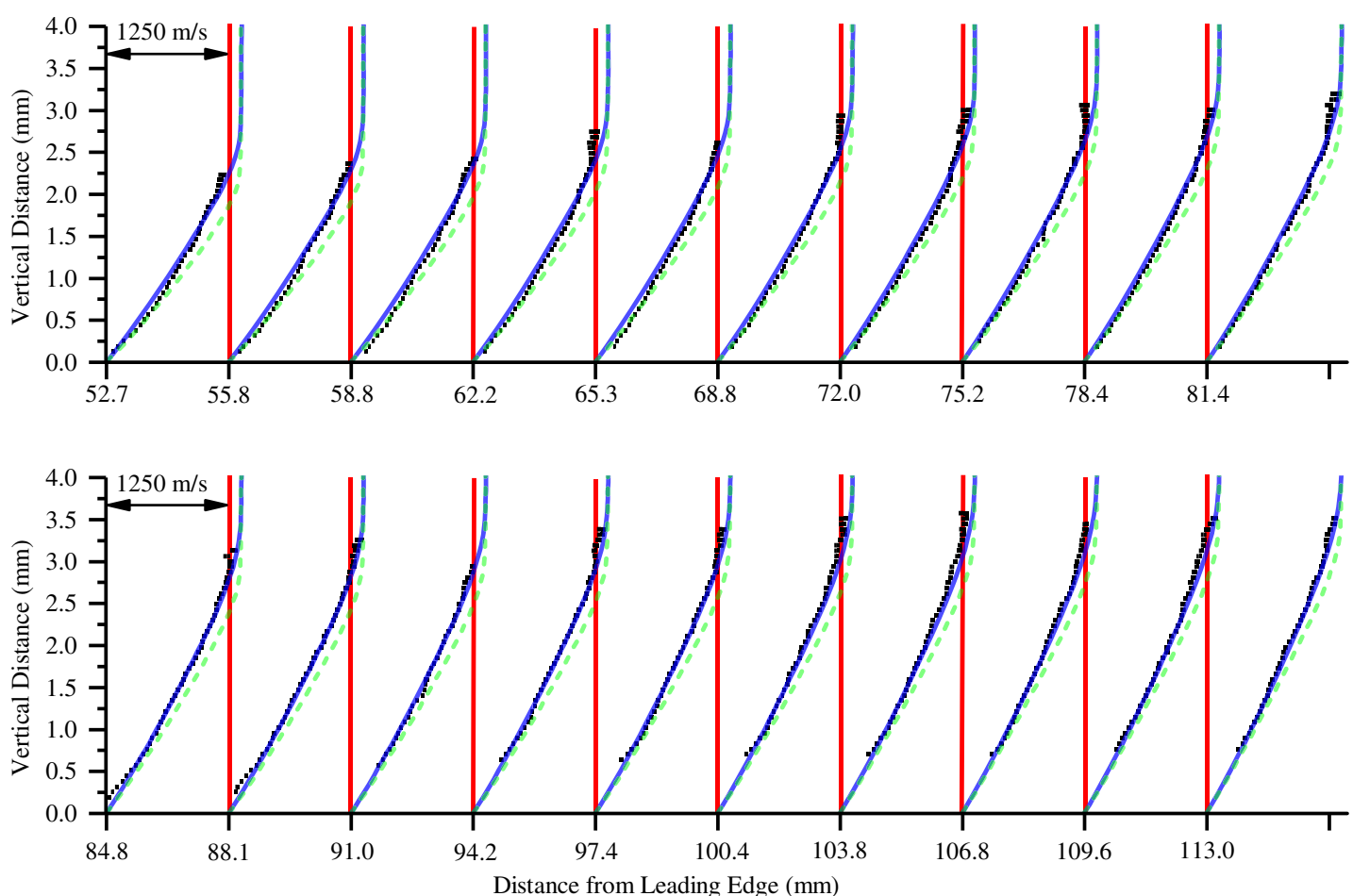

Fig. 10 Comparison of computed and experimental streamwise velocity profiles. Computed profiles are with (solid lines) and without (dashed lines) $\dot{m}_{\mathrm{NO}}=3 \mathrm{mg} / \mathrm{s}$.

determine if the computed flowfield accurately captures the leadingedge hypersonic viscous interaction. For this second comparison, the average measured wall pressure from five separate wind tunnel runs was computed. Each average measurement was computed after the wall pressure sensor (Druck PDCR 4060; 0.04\% accuracy up to $34.5 \mathrm{kPa}$ ) reading stabilized. The mean wall pressure of the five runs was then computed along with the uncertainty in the mean. Figure 11 shows the mean wall pressure measurement divided by the estimated postshock far-field pressure obtained with an inviscid oblique shock calculation. This measurement is plotted against the streamwise wall pressure distribution divided by the postshock farfield pressure $(200.9 \mathrm{~Pa})$. This computed pressure distribution is along the model centerline with no simulated seeding. As can be seen, the simulation (solid curve) accurately predicts the elevated wall pressure caused by the viscous interaction. The dashed curve in this figure represents the pressure ratio in the absence of a hypersonic viscous interaction.

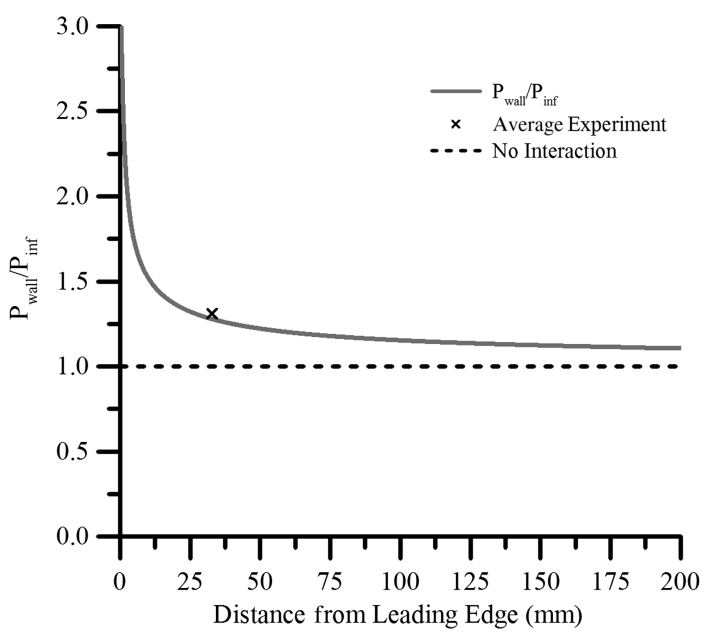

Fig. 11 Comparison of computed streamwise wall pressure along the model centerline with measured mean wall pressure at $x=33 \mathrm{~mm}$ downstream of leading edge.

\section{Comparison of Seed Gases}

The simulation results of boundary-layer flow with only diffusive gas seeding are presented in Sec. VII.A [46]. The overall flowfield is described, and the results are compared to theory. In Sec. VII.B, the effects of jet-in-crossflow interaction on the velocity profile are presented [46]. Results are presented for the ANSYS Fluent simulations.

\section{A. Boundary-Layer Flow with Diffusive Gas Seeding}

Figure 12 shows distributions of pressure, temperature, and NO species mass fraction from a simulation of flow over the flat plate with diffusive gas seeding of NO. The jet inflow was specified as a no-slip wall boundary with a diffusion flux of the NO. The setup is equivalent to the simulation of a jet with a negligible mass flow rate. Only trace levels of the NO are able to diffuse into the velocity boundary layer. Simulations were also performed with the jet boundary specified as a no-slip wall boundary without a diffusive flux. The predictions of velocity, pressure, and temperature were unaffected by the diffusive gas seeding. Stream traces are overlaid onto the respective contour maps. From the pressure and temperature fields, the location of the oblique shock wave is visible. The location of the oblique shock coincides with the redirection of the stream traces parallel to the plate surface. Inclusion of the oblique shock wave in the simulation was preferred over using postshock conditions for the inflow boundary condition to improve overall accuracy. In addition, using postshock conditions would not properly include leading-edge hypersonic viscous interaction effects. These leading-edge effects, which are included in the simulation, cause a large pressure rise at the near-wall region of the inflow boundary as the boundary layer begins to form. Since there is no jet velocity, the mass fraction levels of NO are very low, the influence of which is undetectable from the pressure and temperature contour maps. Although low in concentration, the gas is able to diffuse several millimeters away from the surface after $100 \mathrm{~mm}$ downstream of the leading edge.

Figure 13 shows the growth of the concentration and velocity boundary layer for cases with $\mathrm{NO}, \mathrm{I}_{2}$, and $\mathrm{Kr}$ diffusive seeding $(0 \mathrm{mg} / \mathrm{s})$. Simulation predictions of the concentration boundarylayer growth are compared to theory [Eq. (1)]. In the application of Eq. (1), Schmidt numbers of $S c=0.75,0.8 \overline{9}$, and 1.35 were used for 


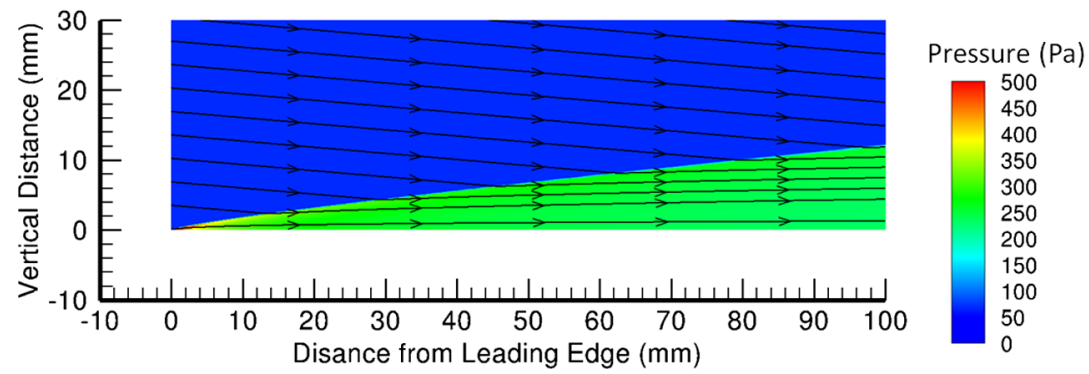

a)

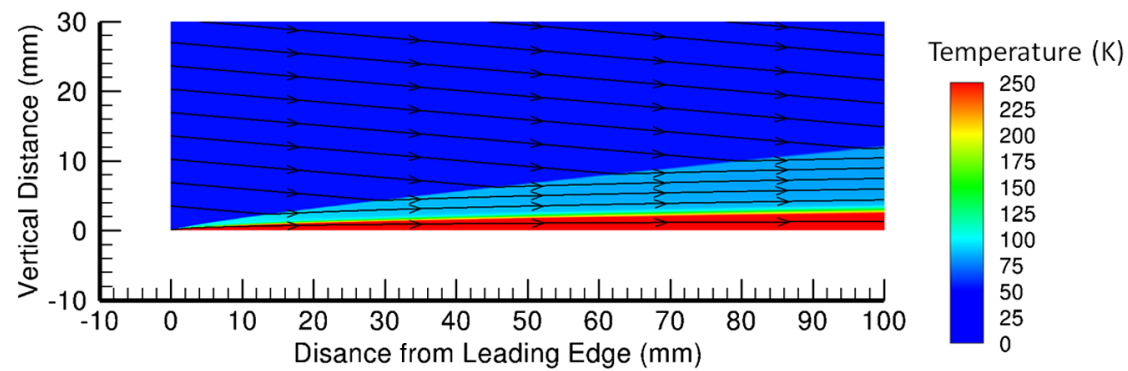

b)

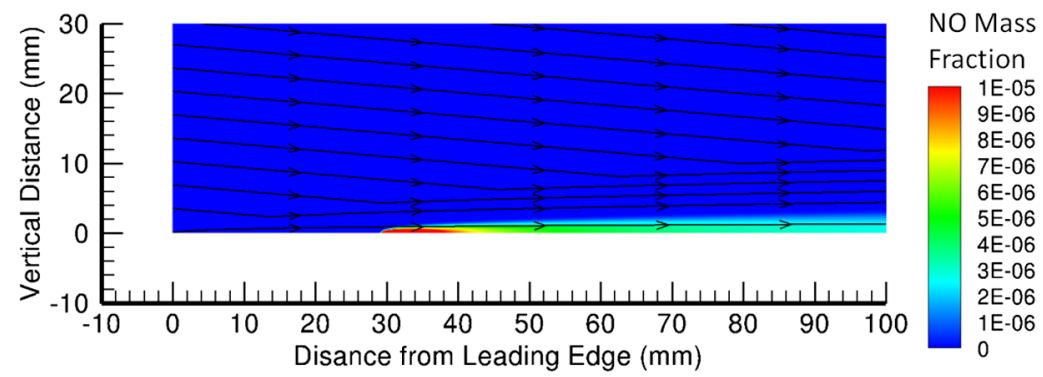

c)

Fig. 12 Fields of a) pressure, b) temperature, and c) concentration (diffusive flux only).

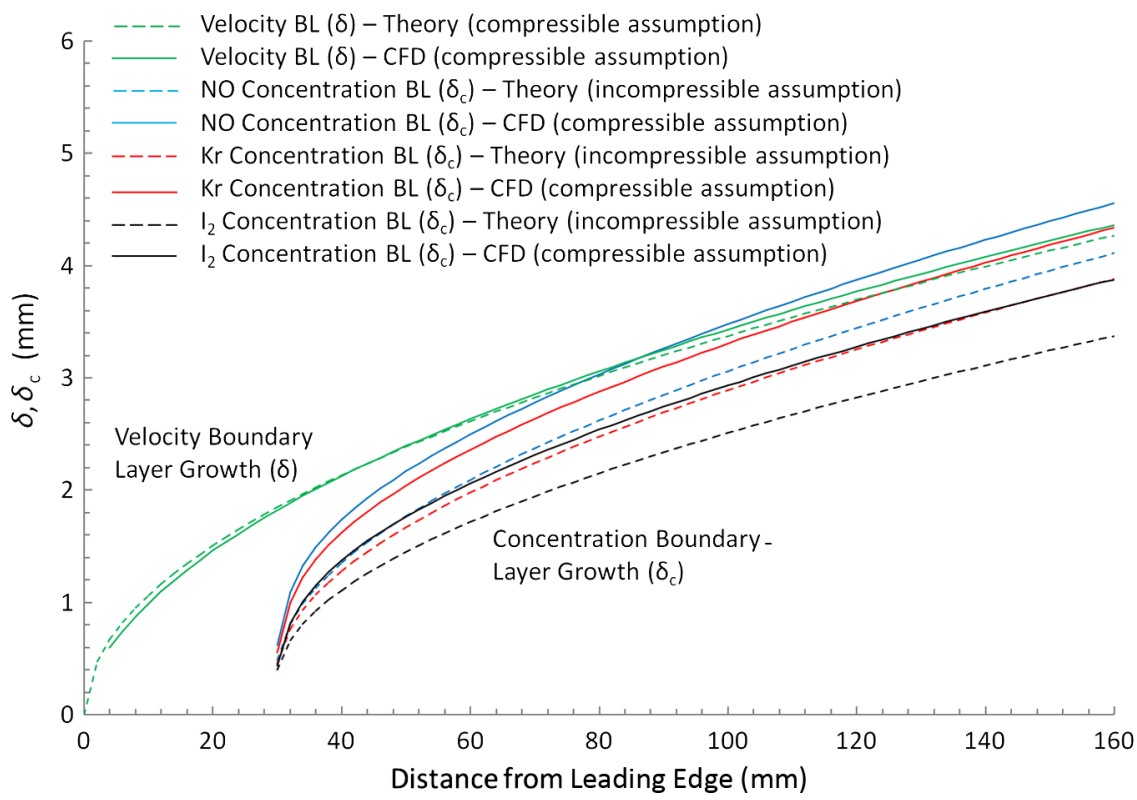

Fig. 13 Theoretical and numerical prediction of velocity and concentration boundary-layer (BL) growth for NO, Kr, and $\mathrm{I}_{2}$ (diffusive flux only).

$\mathrm{NO}, \mathrm{Kr}$, and $\mathrm{I}_{2}$ gases, respectively. The velocity and concentration boundary-layer thicknesses based on the simulation data were determined through postprocessing and defined as the vertical location where $U_{x} / U_{e}=0.99$ and $\left(1-w_{c}\right) /\left(1-w_{c, \max }\right)=0.99$, respectively. The mass fraction of the species of interest is denoted as $w_{c}$, and the velocity at the edge of the boundary layer is denoted $U_{e}$. A combination of Tecplot macro scripts and $\mathrm{C}++$ was used to postprocess the data. The theoretical velocity boundary-layer growth was determined from the Virginia Tech (VT) CLBL solver [45]. There is good agreement between the simulated and theoretical 
velocity boundary-layer profiles. Small differences are attributed to approximations in the postshock conditions used for the inputs of the VT CLBL solver and approximation of fluid properties. In addition, there is good qualitative agreement between the simulation and theory in predicting the trends in the rates of mass diffusion for each gas. For example, the results show that heavier gases diffuse more slowly than the lighter gases. The theory, however, does underpredict the absolute rates of mass diffusion for each of the seeded gases in comparison to the simulation. Since Eq. (1) is based on incompressible boundary-layer assumptions, the theory is not expected to accurately predict the absolute growth rate of the concentration boundary layer. The simulations show that only the NO concentration boundary-layer thickness eventually overtakes $(x=85 \mathrm{~mm})$ the velocity boundary layer before the end of the plate. $\mathrm{Kr}$ and $\mathrm{I}_{2}$ remain contained within the velocity boundary layer along the entire length of the plate. Although, $\mathrm{Kr}$ would, and $\mathrm{I}_{2}$ might, eventually approach and exceed the velocity boundary-layer edge on a longer plate.

\section{B. Boundary-Layer Flow with Jet Gas Seeding}

Figure 14 shows distributions of temperature, pressure, and NO mass fraction from a simulation with gas seeding at a finite mass flow rate. In these simulations, $\mathrm{NO}$ is seeded through the jet inflow boundary at a standard flow rate of 150 SCCM. This flow rate was selected to match the experimental rate used for the majority of PLIF MTV measurements in previous work [43]. At standard conditions, this flow rate corresponds to a mass flow rate of approximately $\dot{m}=3 \mathrm{mg} / \mathrm{s}$. A bow shock wave ahead of the jet is visible in the pressure and temperature fields. Although much weaker than the upstream oblique shock wave, the bow shock wave causes a small deflection in the velocity field near the NO jet. Although subtle, both the temperature and velocity boundary-layer thicknesses are slightly larger compared to images in Fig. 12. Similar to the diffusive seeding case, NO still remains concentrated near the wall surface (see Fig. 12c) but with concentration levels much larger than that found in the diffusive seeding case.

Figure 15 shows the effect of the seeded gas mass flow rate on the respective concentration boundary-layer thicknesses. The results indicate that an increase in mass flow rate from $\dot{m}=0 \mathrm{mg} / \mathrm{s}$ (diffuse seeding) to $\dot{m}=3 \mathrm{mg} / \mathrm{s}$ causes a noticeable increase in the thickness for each case simulated. For example, at $x=106 \mathrm{~mm}$, the increases in concentration boundary-layer thicknesses are 3.6, 4.8, and $2.9 \%$ for $\mathrm{NO}, \mathrm{Kr}$, and $\mathrm{I}_{2}$ seeded gases, respectively. In addition to the diffusion of mass, the finite momentum of the seeded gas allows convection deeper into the velocity boundary layer. The original velocity boundary layer has been included in the figure as a reference. To avoid clutter in the figure, the corresponding velocity boundarylayer profiles have not been included, and they are instead shown in the following figure.

Figure 16 shows the influence of the gas seeding on the velocity boundary-layer thickness profiles. In these profiles, the corresponding mass flow injection rates of $\mathrm{NO}, \mathrm{Kr}$, and $\mathrm{I}_{2}$ were $\dot{m}=3 \mathrm{mg} / \mathrm{s}$. The results indicate that the injection of $\mathrm{NO}$ causes a slightly larger deflection in the velocity field than the other gases. Since the mass flow rate is equivalent in each case, a large difference between the predicted magnitudes of deflection is not expected. Although each seeded gas is able to convect further from the wall because of higher seeding flow rates, the streamwise location at which the concentration boundary layer intersects with the velocity boundary layer actually increases because of the increased thickness of the boundary layer. For example, the streamwise distance of this intersection for NO seeding increases from $85 \mathrm{~mm}$ (Fig. 15) to $100 \mathrm{~mm}$ (Fig. 16) when the jet mass flow rate increases from $\dot{m}=0 \mathrm{mg} / \mathrm{s}$ to

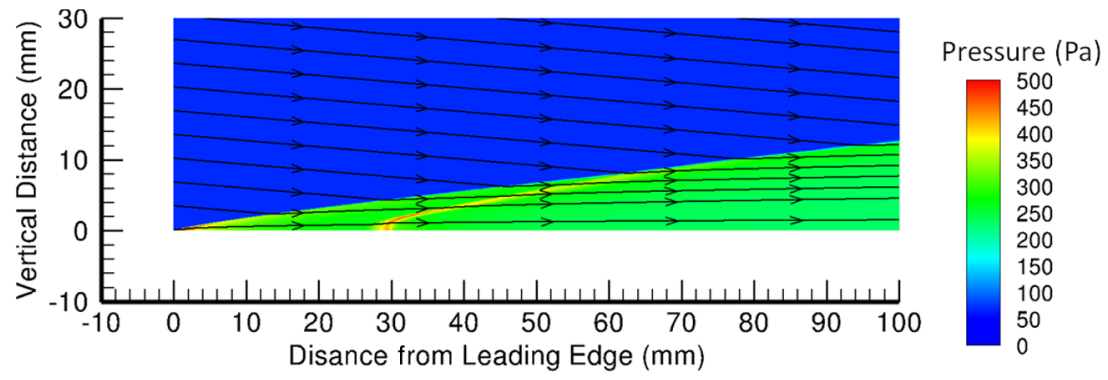

a)

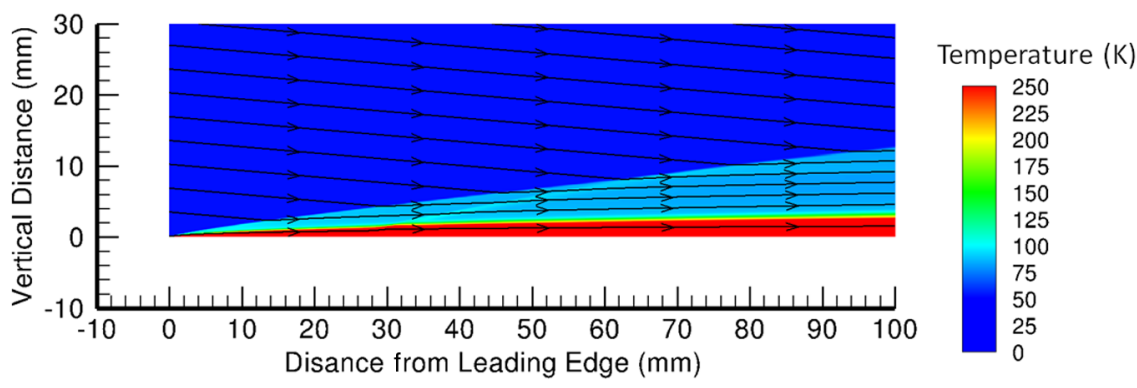

b)

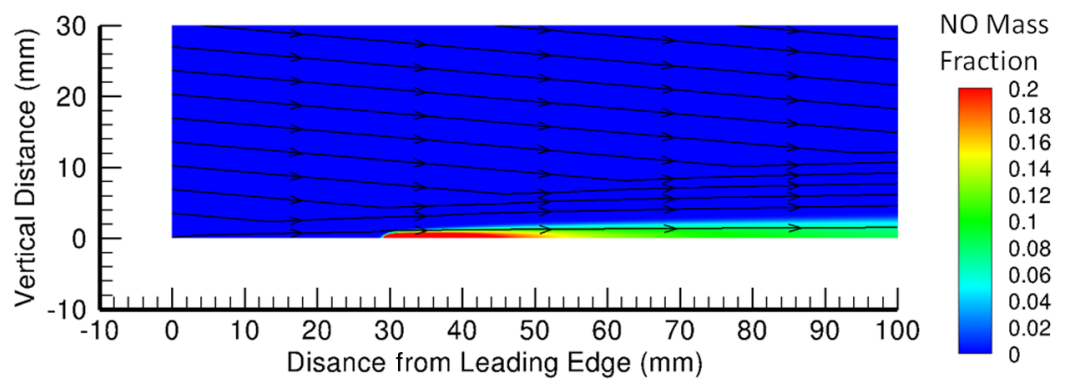

c)

Fig. 14 Fields of a) pressure, b) temperature, and c) concentration. Stream traces overlaid to show velocity direction. NO gas-seeding flow rate is $3 \mathrm{mg} / \mathrm{s}$. 


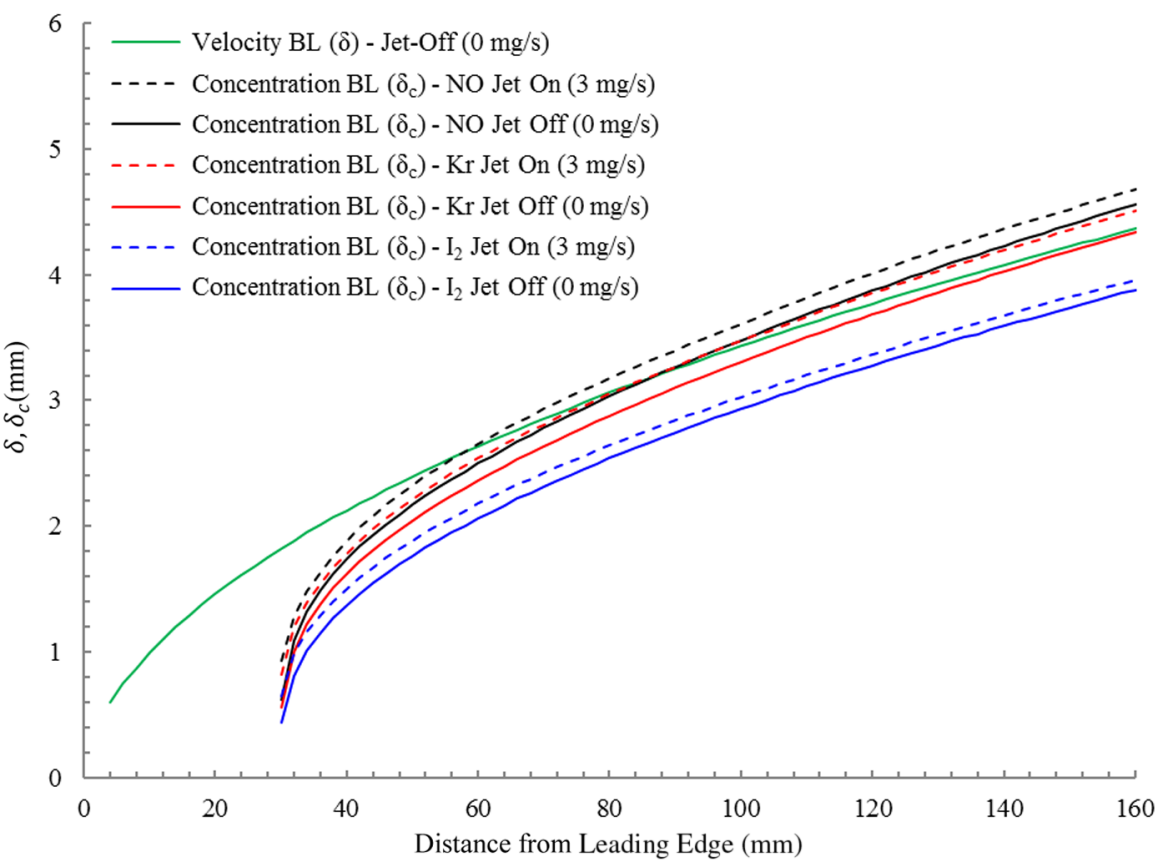

Fig. 15 Effect of blowing on numerical prediction of concentration boundary-layer growth for NO, Kr, and $\mathrm{I}_{2}$.

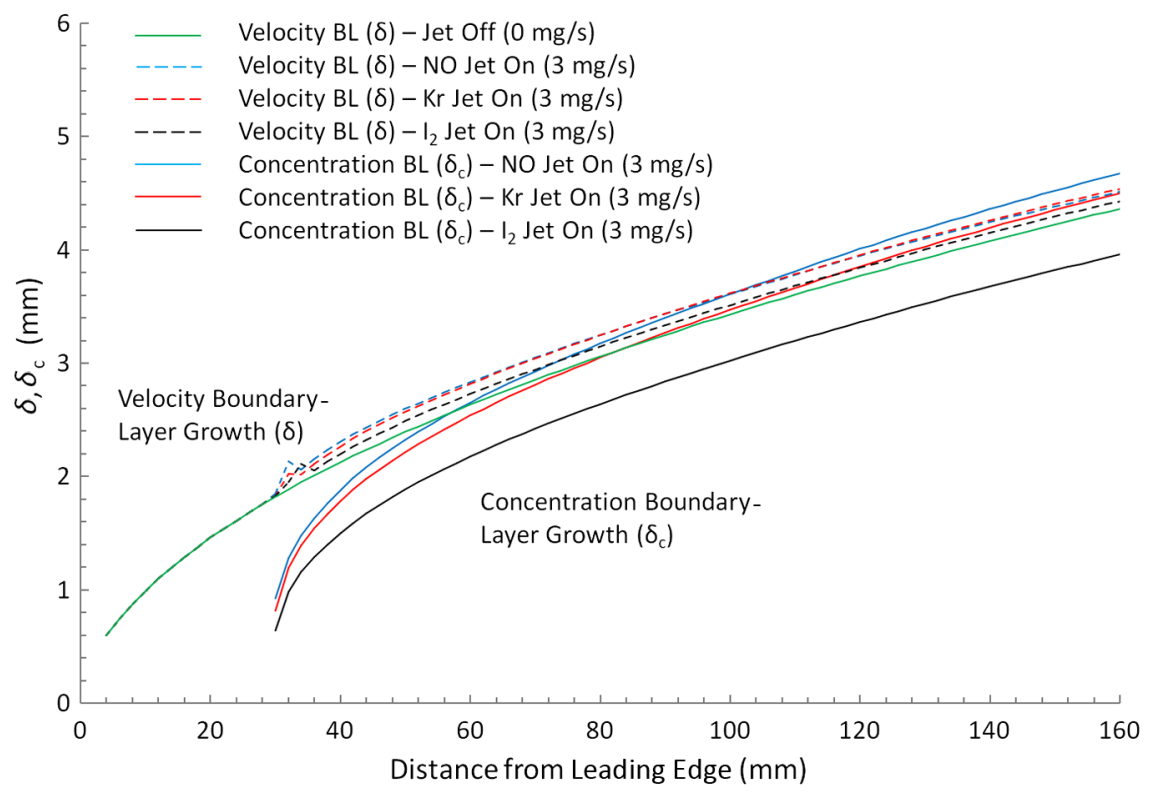

Fig. 16 Deflection of velocity boundary-layer profile from NO, Kr, and $I_{2}$ seeding. $\dot{m}=3 \mathrm{mg} / \mathrm{s}$.

$\dot{m}=3 \mathrm{mg} / \mathrm{s}$. In both $\mathrm{Kr}$ seeding cases, the concentration layer thickness approaches the velocity boundary-layer thickness near the end of the figure $(x=160 \mathrm{~mm})$. Herein, only cases with a corresponding jet mass flow rate of $\dot{m}=3 \mathrm{mg} / \mathrm{s}$ will be analyzed. Experimentally, this minimum flow rate was required to achieve acceptable PLIF signal levels (NO gas seeding) [43]. The seed gas jet Reynolds numbers corresponding to this seed gas flow rate based on the jet slot width were 185,140 , and 225 for $\mathrm{NO}, \mathrm{Kr}$, and $\mathrm{I}_{2}$, respectively.

The initial deflections of the velocity boundary-layer thickness profile for the $\mathrm{NO}$ and $\mathrm{Kr}$ seeding cases occur further upstream compared to the deflection associated with the $\mathrm{I}_{2}$ seeding case. Deflections occurring further upstream are caused by higher jet velocities associated with the seeded gas. Figure 17 shows contour maps of the species mass fraction with velocity stream traces overlaid for each respective seeded gas near each jet inflow boundary. The scale in the vertical direction has been expanded to help illustrate the adverse effects that the gas seeding has on the velocity field. Since
$\mathrm{NO}$ has a lower molecular mass than both $\mathrm{Kr}$ and $\mathrm{I}_{2}$, the jet velocity increases to satisfy the conservation of mass.

Although the analysis of the concentration boundary-layer thickness is useful for understanding the maximum extents that each seeded gas will advect and diffuse in the vertical direction, it is also important to analyze the vertical distributions of mass distribution for each case. Figure 18 shows distributions of velocity, temperature, and species mass fraction for cases with $\mathrm{NO}, \mathrm{Kr}$, and $\mathrm{I}_{2}$ seeded gases ( $\dot{m}=3 \mathrm{mg} / \mathrm{s}$ ). These profiles are compared to a jet-off case, where gas is not injected through the jet-inflow boundary. These profiles are located $106 \mathrm{~mm}$ downstream of the plate's leading edge. Similar to observations from the effect of gas seeding on the velocity boundarylayer thickness predictions, the velocity and temperature fields are slightly affected by the seeding process ( $\dot{m}=3 \mathrm{mg} / \mathrm{s}$ ).

The distribution of $\mathrm{I}_{2}$ compared to both $\mathrm{NO}$ and $\mathrm{Kr}$ has implications for any potential PLIF signal that could be measured near the edge of the velocity boundary layer. $\mathrm{I}_{2}$ remains more concentrated near the wall boundary, which suggests that PLIF 

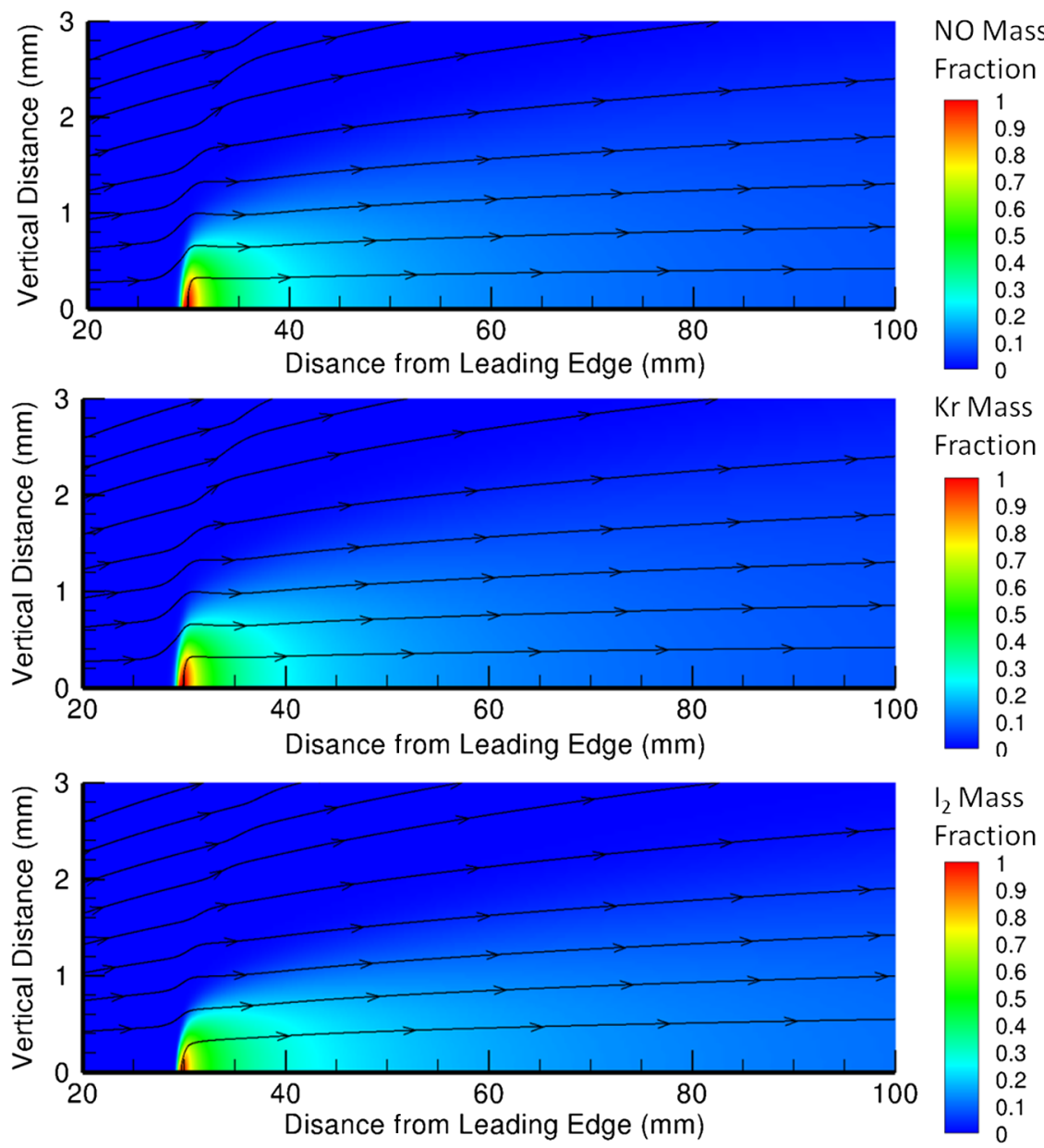

Fig. 17 Deflection of velocity field from a) NO, b) $\mathrm{Kr}$, and c) $\mathrm{I}_{2}$ gas seeding. $\dot{m}=3 \mathrm{mg} / \mathrm{s}$.

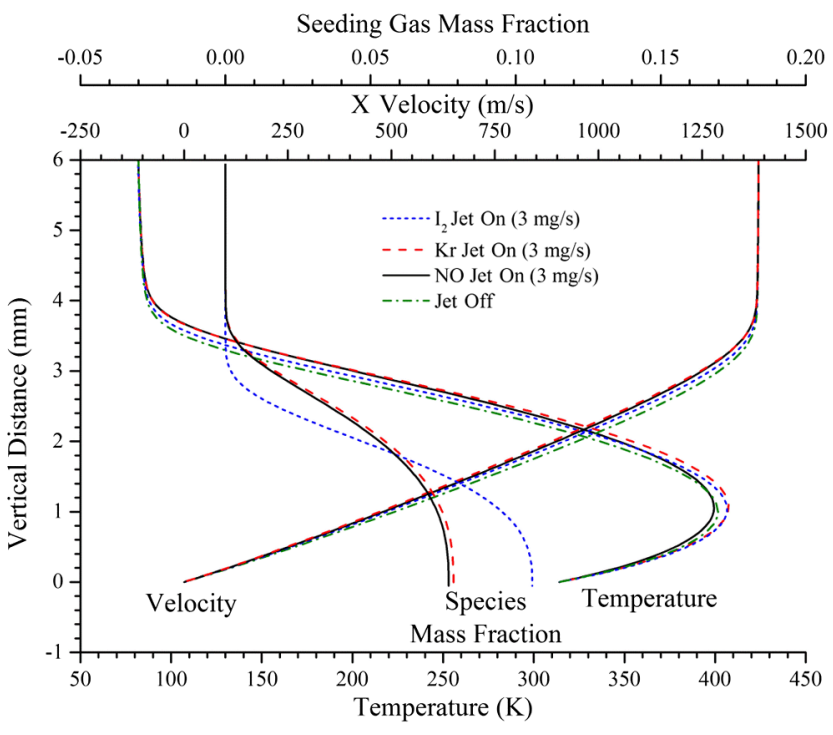

Fig. 18 Distributions of velocity, species, and temperature for $\mathrm{NO}, \mathrm{Kr}$, and $\mathrm{I}_{2}$ gas-seeding techniques. $\dot{m}=3 \mathrm{mg} / \mathrm{s}$.

signals for $\mathrm{I}_{2}$ seeding would be lower than PLIF signals with $\mathrm{NO}$ or $\mathrm{Kr}$ seeding near the edge of the velocity boundary layer (assuming the same mass flow rate). At this streamwise position, the thermal boundary layer based on the temperature profile is approximately $15 \%$ thicker than the velocity boundary layer. As a result, an NO PLIF signal can be obtained across the full velocity boundary layer, but it will not be available at the outer edges of the temperature boundary layer. This is an important result because transition from laminar to turbulent flow has been reported to occur at the edge of the boundary layer in hypersonic flows [19]. At the end of the computation domain $(x=200 \mathrm{~mm})$, the NO concentration layer was still smaller than the temperature boundary layer. The vertical distribution of mass associated with each seeded gas is affected by the distribution of local Schmidt numbers. As the seeded gas mixes with the crossflow, changes in temperature and mixture composition affect levels of viscosity, density, and mass diffusion rates. Figure 19 shows a vertical Schmidt number distribution for each seeding gas along with a vertical distribution of normalized species mass fraction $106 \mathrm{~mm}$ downstream of the leading edge. As expected, with higher Schmidt numbers, the gas is unable to penetrate far into the boundary layer.

Interestingly, the difference in the Schmidt number between each seeded gas is lower near the wall surface than at the edge of the velocity boundary layer. As a result, the diffusion rate of $\mathrm{I}_{2}$ relative to NO is much lower at the edge of the velocity boundary layer. This causes $\mathrm{I}_{2}$ to remain more concentrated near the wall surface, whereas $\mathrm{NO}$ and $\mathrm{Kr}$ concentrations become more distributed with downstream distance. Note that the difference in Schmidt number between each seeded gas only varies by a factor of two, despite the much larger variation in molecular weight (factor of 10). To further understand the distributions of the Schmidt number, Fig. 20 shows the breakdown in thermodynamic quantities that contribute to the dimensionless number [Eq. (2)]. Since the mass fraction of the seeded gas is low at this streamwise location, the local density and viscosity are not largely affected by the jet composition. Near the wall surface, viscous heating causes the gas temperature to rise, which acts to both decrease the local gas density and increase the local dynamic viscosity. This combination alone would result in an increase in the Schmidt number, which would inhibit the growth of the concentration boundary layer relative to the velocity boundary layer. The local diffusion coefficient for each gas, however, is dependent on the jet composition and gas temperature. Based on kinetic theory, a 


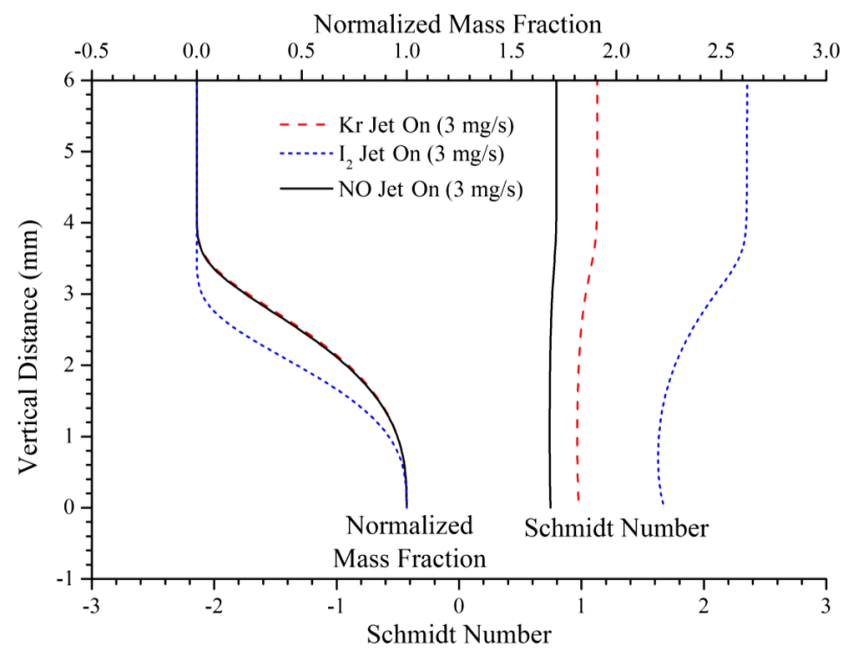

Fig. 19 Schmidt number and mass diffusion of gas. $\dot{m}=3 \mathrm{mg} / \mathrm{s}$.

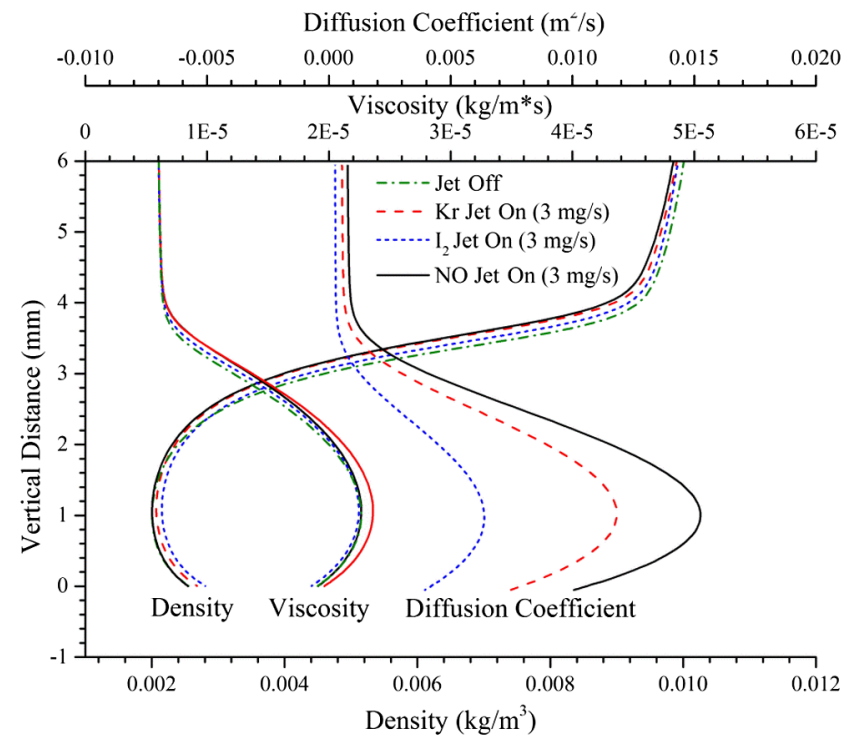

Fig. 20 Components of the gas Schmidt number. $\dot{m}=3 \mathrm{mg} / \mathrm{s}$.

rise in gas temperature is accompanied with a corresponding rise in the binary diffusion coefficient. The total combination of these changes in thermodynamic properties causes the Schmidt number to decrease near the wall surface, promoting growth of the concentration boundary layer relative to the velocity boundary layer.

\section{Discussion}

In addition to the aforementioned comparisons between gases, practical implications should be considered when comparing the three seed gases included in this study. Examples of the use of $\mathrm{Kr}$ and $I_{2}$ in PLIF experiments can be found in [47] for $\mathrm{Kr}$ and $[48,49]$ for $\mathrm{I}_{2}$. Each of the seeded gases needs adequate gas handling equipment to ensure the safety of human operators near the wind-tunnel apparatus. $\mathrm{NO}$ and $\mathrm{I}_{2}$ are toxic if inhaled at low concentrations, though $\mathrm{NO}$ is relatively more toxic than $\mathrm{I}_{2}$ [50]; NO requires special gas handling equipment with increased safety concerns. In comparison, $\mathrm{Kr}$ is a nontoxic asphyxiant, easing the restrictions required for gas handling compared to $\mathrm{NO}$ and $\mathrm{I}_{2}$. The molecular weights of $\mathrm{NO}, \mathrm{Kr}$, and $\mathrm{I}_{2}$ are 30,84 , and $254 \mathrm{~g} / \mathrm{mol}$, respectively. With artificial seeding, it is preferable to match the molecular weight of the freestream gas $\left(\mathrm{MW}_{\mathrm{air}} \sim 29 \mathrm{~g} / \mathrm{mol}\right)$. The thermal conductivity, molecular viscosity, and mass diffusivity are all dependent on the molecular weight of the seeded gas. Depending on the pressure, NO can quickly react with oxygen at the low temperatures that typically occur in hypersonic ground facilities [51]. In contrast, $\mathrm{Kr}$ and $\mathrm{I}_{2}$ do not react with air.
It is worth noting that the comparisons were made while holding the mass flow rate constant. As a result, fewer molecules of $\mathrm{Kr}$ and $\mathrm{I}_{2}$ were injected into the flow than $\mathrm{NO}$; therefore, the laser induced fluorescence (LIF) signals from the various species will be different. The LIF signal is not only dependent on the concentration of the fluorescence species, but it is also dependent on other parameters including collisional quenching, which affects the fluorescence yield, and laser saturation. As a result, holding the molar flow rate constant would not be any better of a comparison. By using fluorescence models to predict the LIF signal based on the thermodynamic properties of the flow, a better comparison between seeding techniques could be obtained.

In addition to a LIF signal-based comparison, additional flow physics and run conditions may be worth considering to further expand the study. For example, the influence of the plate angle has a large effect on the postshock conditions, which changes the interaction between the jet and crossflow. Furthermore, possible reactions between $\mathrm{NO}$ and $\mathrm{O}_{2}$ deposit heat into the flow and deplete the concentration of the fluorescent species [51]. Unsteadiness in the seeding might also cause or amplify instability modes in the flow that could lead to the transition to turbulence. Extension of the computational domain into three dimensions in addition to modeling the internal gas-seeding geometry could also be done to study this phenomenon.

In a previous NO PLIF MTV experiment that studied the transition to turbulence in a hypersonic boundary layer, good signal-to-noise levels were achieved with an NO seeding flow rate of 150 SCCM ( $\dot{m}=3 \mathrm{mg} / \mathrm{s}$ ) [43]. The model geometry, test conditions, and plate angle were equivalent to those described in the current study. Experimentally, reducing the flow rate by a factor of 10 in order minimally perturb the flow, as indicated by the CFD results of this work, would result in insufficient PLIF signal levels with the current experimental setup. The flow rate could be reduced if changes were made to either the laser excitation or the detection system. Obvious improvements to the excitation system include a more powerful laser source (though saturation of the fluorescence transition can limit the laser energy used), exciting a stronger transition, or broadening the line width of the laser to excite more of the molecules in the Dopplerbroadened Voigt profile. The detection system could be improved by using a larger UV lens to collect more light or using an intensified charge-coupled device (CCD) camera with higher quantum efficiency or a more efficient coupling between the intensifier and the CCD.

The OpenFOAM results show excellent agreement when compared to the ANSYS Fluent results. As a result, the difference between the coupled and segregated methods that the two CFD solvers use can be considered negligible from a results standpoint for the cases investigated. The results were also found to be independent of the shock capturing scheme; similar shock locations and gradients were found for both solvers. Dynamic mesh refinement is also determined to be applicable to this problem, as the ANSYS Fluent mesh resulted in a solution that agreed with the manually created OpenFOAM mesh solution.

\section{Conclusions}

The OpenFOAM-version-2.2.1-based solver rhoCentralBinaryFoam was introduced and validated against results from the commercial CFD package ANSYS Fluent version 6.3. Excellent agreement was shown between the two CFD codes, and confidence in the rhoCentralBinaryFoam solver has been established for future CFD studies.

Predictions of the velocity boundary-layer thickness agree well with Virginia Tech's CLBL code. Although based on incompressible assumptions, the analytical expression [Eq. (1)] agrees with the trends of the numerical predictions of the relative concentration boundary-layer growth for each seeded gas. Additionally, simulation results for NO seeded at a flow rate of $3 \mathrm{mg} / \mathrm{s}$ show excellent agreement with the experimental MTV and pressure tap data.

It was found that increasing the seeded gas jet mass flow rate results in an increase in species concentration but does not increase 
the growth rate of the concentration boundary layer relative to the velocity boundary layer. For a fixed jet mass flow rate of $\dot{m}=3 \mathrm{mg} / \mathrm{s}$, each of the species investigated (NO, $\mathrm{Kr}$, and $\mathrm{I}_{2}$ ) perturbed the velocity boundary layer $\left(\mathrm{I}_{2}\right.$ the least, and NO the most). Further analysis of the local distribution of the Schmidt number showed why $\mathrm{I}_{2}$ remains concentrated near the wall surface, whereas $\mathrm{NO}$ and $\mathrm{Kr}$ become more distributed toward the edge of the velocity boundary layer. For the jet flow rates simulated, NO is the only seeded gas to penetrate beyond the edge of the velocity boundary layer (though not the thermal boundary layer) before reaching the end of the plate. Although much heavier than $\mathrm{NO}$, both $\mathrm{Kr}$ and $\mathrm{I}_{2}$ were found to diffuse far into the velocity boundary layer, allowing PLIF to be used with these seeding techniques, albeit closer to the wall than for NO.

\section{Acknowledgments}

C. T. Johansen and C. Arisman were supported by the Natural Sciences and Engineering Research Council of Canada. This work was supported by the NASA Fundamental Aeronautics Program, Hypersonics Project, Aerodynamics-Aerothermodynamics-Plasma Discipline.

\section{References}

[1] Khose-Höinghaus, K., and Jeffries, J. B., Applied Combustion Diagnostics, Taylor and Francis, New York, 2002, pp. 9-47.

[2] Fox, J. S., Houwing, A. F. P., Danehy, P. M., Gaston, M. J., Mudford, N. R., and Gai, S. L., "Mole-Fraction-Sensitive Imaging of Hypermixing Shear Layers," Journal of Propulsion and Power, Vol. 17, No. 2, March 2001, pp. 284-292.

doi: $10.2514 / 2.5775$

[3] Inman, J. A., Danehy, P. M., Alderfer, D. W., Jones, S. B., and Patry, D. P., "Planar Fluorescence Imaging and Three-Dimensional Reconstructions of Capsule Reaction-Control-System Jets," AIAA Journal, Vol. 47, No. 4, April 2009, pp. 803-812. doi: $10.2514 / 1.37116$

[4] Danehy, P. M., Inman, J. A., Brauckmann, G. J., Alderfer, D. W., Jones, S. B., and Patry, D. P., "Visualization of a Capsule Entry Vehicle Reaction-Control System Thruster," Journal of Spacecraft and Rockets, Vol. 46, No. 1, Jan. 2009, pp. 93-102. doi: $10.2514 / 1.34846$

[5] Combs, C., Clemens, N. T., and Danehy, P. M., "Development of Naphthalene PLIF for Visualizing Ablation Products from a Space Capsule Heat Shield," 52nd Aerospace Sciences Meeting, AIAA Paper 2014-1152, 2014.

[6] Bathel, B., Danehy, P., Inman, J., Alderfer, D., and Berry, S., "PLIF Visualization of Active Control of Hypersonic Boundary Layers Using Blowing," 26th AIAA Aerodynamic Measurement Technology and Ground Testing Conference, AIAA Paper 2008-4266, 2008.

[7] Medford, T., Danehy, P., Jones, S., Jiang, N., Webster, M., Lempert, W., Miller, J., and Meyer, T., "Stereoscopic Planar Laser-Induced Fluorescence Imaging at $500 \mathrm{kHz}, "$ 49th AIAA Aerospace Sciences Meeting Including the New Horizons Forum and Aerospace Exposition, AIAA Paper 2011-0985, 2011.

[8] Bathel, B., Danehy, P., Inman, J., Watkins, A., Jones, S., Lipford, W., Goodman, K., Ivey, C., and Goyne, C., "Hypersonic Laminar Boundary Layer Velocimetry with Discrete Roughness on a Flat Plate," 40th Fluid Dynamics Conference and Exhibit, AIAA Paper 2010-4998, 2010.

[9] Danehy, P., Ivey, C., Inman, J., Bathel, B., Jones, S., Jiang, N., Webster, M., Lempert, W., Miller, J., Meyer, T., and McCrea, A. C., "High-Speed PLIF Imaging of Hypersonic Transition over Discrete Cylindrical Roughness," 48th AIAA Aerospace Sciences Meeting Including the New Horizons Forum and Aerospace Exposition, AIAA Paper 2010-0703, 2010.

[10] Danehy, P., Ivey, C., Bathel, B., Inman, J., Jones, S., Jiang, N., Webster, M., Lempert, W., Miller, J., Meyer, T., Watkins, A. N., and Goodman, K. Z., "Orbiter BLT Flight Experiment Wind Tunnel Simulations: Nearfield Flowfield Imaging and Surface Thermography," 48th AIAA Aerospace Sciences Meeting Including the New Horizons Forum and Aerospace Exposition, AIAA Paper 2010-1571, 2010.

[11] Horvath, T. J., Berry, S., Merski, N., Berger, K., Buck, G., Leichty, D., and Schneider, S., "Shuttle Damage/Repair from the Perspective of Hypersonic Boundary Layer Transition-Experimental Results," 9th AIAA/ASME Joint Thermophysics and Heat Transfer Conference, AIAA Paper 2006-2919, 2006.
[12] Schneider, S. P., "Effects of Roughness on Hypersonic Boundary-Layer Transition," Journal of Spacecraft and Rockets, Vol. 45, No. 2, March 2008, pp. 193-209. doi: 10.2514/1.29713

[13] Saric, W. S., "Görtler Vortices," Annual Review of Fluid Mechanics, Vol. 26, No. 1, Jan. 1994, pp. 379-409. doi:10.1146/annurev.fl.26.010194.002115

[14] Mack, L. M., Boundary Layer Linear Stability Theory, Pasadena, CA, 1984, pp. 1-81.

[15] Saric, W. S., Reed, H. L., and White, E. B., "Stability and Transition of Three-Dimensional Boundary Layers," Annual Review of Fluid Mechanics, Vol. 35, No. 1, Jan. 2003, pp. 413-440. doi:10.1146/annurev.fluid.35.101101.161045

[16] Arnal, D., and Casalis, G., "Laminar-Turbulent Transition Prediction in Three-Dimensional Flows," Progress in Aerospace Sciences, Vol. 36, No. 2, Feb. 2000, pp. 173-191. doi:10.1016/S0376-0421(00)00002-6-0421(00)00002-6

[17] Danehy, P. M., Bathel, B., Ivey, C., Inman, J., and Jones, S., "NO PLIF Study of Hypersonic Transition over a Discrete Hemispherical Roughness Element," AIAA Paper 2009-0394, 2009.

[18] Micol, J., "Langley Aerothermodynamic Facilities ComplexEnhancements and Testing Capabilities," 36th AIAA Aerospace Sciences Meeting and Exhibit, AIAA Paper 1998-0147, 1998.

[19] Fischer, M. C., "Spreading of a Turbulent Disturbance," AIAA Journal, Vol. 10, No. 7, July 1972, pp. 957-959. doi: $10.2514 / 3.50265$

[20] Anderson, J. D., Hypersonic and High Temperature Gas Dynamics, AIAA, Reston, VA, 2000, pp. 301-332.

[21] Asano, K., Mass Transfer: From Fundamentals to Modern Industrial Applications, Wiley, New York, 2006, pp. 70-73.

[22] Svehla, R. A., "Estimated Viscosities and Thermal Conductivities of Gases at High Temperatures," NASA TR-R-132, Lewis Research Center, Cleveland, OH, 1962.

[23] Stalker, R. J., "Control of Hypersonic Turbulent Skin Friction by Boundary-Layer Combustion of Hydrogen," Journal of Spacecraft and Rockets, Vol. 42, No. 4, July 2005, pp. 577-587. doi: $10.2514 / 1.8699$

[24] Goyne, C. P., Stalker, R. J., Paull, A., and Brescianini, C. P., "Hypervelocity Skin-Friction Reduction by Boundary-Layer Combustion of Hydrogen," Journal of Spacecraft and Rockets, Vol. 37, No. 6, Nov. 2000, pp. $740-746$. doi: $10.2514 / 2.3645$

[25] Jewell, J., Wagnild, R., Leyva, I., Candler, G., and Shepherd, J., "Transition Within a Hypervelocity Boundary Layer on a 5-Degree Half-Angle Cone in Air/ $/ \mathrm{CO}_{2}$ Mixtures," 51 st AIAA Aerospace Sciences Meeting Including the New Horizons Forum and Aerospace Exposition, AIAA Paper 2013-0523, 2013.

[26] Greenshields, C. J., Weller, H. G., Gasparini, L., and Reese, J. M., "Implementation of Semi-Discrete, Non-Staggered Central Schemes in a Colocated, Polyhedral, Finite Volume Framework, for High-Speed Viscous Flows," International Journal for Numerical Methods in Fluids, Vol. 63, No. 1, May 2010, pp. 1-21. doi:10.1002/fld.2069

[27] Roe, P., "Characteristic-Based Schemes for the Euler Equations," Annual Review of Fluid Mechanics, Vol. 18, No. 1, Jan. 1986, pp. 337-365. doi:10.1146/annurev.fl.18.010186.002005

[28] Nessyahu, H., and Tadmor, E., "Non-Oscillatory Central Differencing for Hyperbolic Conservation Laws," Journal of Computational Physics, Vol. 87, No. 2, April 1990, pp. 408-463. doi:10.1016/0021-9991(90)90260-8-9991(90)90260-8

[29] Kurganov, A., and Tadmor, E., "New High-Resolution Central Schemes for Nonlinear Conservation Laws and Convection-Diffusion Equations," Journal of Computational Physics, Vol. 160, No. 1, May 2000, pp. 241-282. doi:10.1006/jcph.2000.6459

[30] Van Leer, B., "Towards the Ultimate Conservative Difference Scheme," Journal of Computational Physics, Vol. 135, No. 2, Aug. 1997, pp. 229 248. doi:10.1006/jcph.1997.5704

[31] Colella, P., and Woodward, P. R., "The Piecewise Parabolic Method (PPM) for Gas-Dynamical Simulations," Journal of Computational Physics, Vol. 54, No. 1, April 1984, pp. 174-201. doi:10.1016/0021-9991(84)90143-8-9991(84)90143-8

[32] Harten, A., Engquist, B., Osher, S., and Chakravarthy, S. R., "Uniformly High Order Accurate Essentially Non-Oscillatory Schemes III," Journal of Computational Physics, Vol. 71, No. 2, Aug. 1987, pp. 231-303. doi:10.1016/0021-9991(87)90031-3

[33] Liu, X.-D., Osher, S., and Chan, T., "Weighted Essentially NonOscillatory Schemes," Journal of Computational Physics, Vol. 115, 
No. 1, Nov. 1994, pp. 200-212. doi: $10.1006 /$ jcph. 1994.1187

[34] Cockburn, B., and Shu, C.-W., "The Runge-Kutta Discontinuous Galerkin Method for Conservation Laws V," Journal of Computational Physics, Vol. 141, No. 2, April 1998, pp. 199-224. doi:10.1006/jcph.1998.5892

[35] Bansal, A., Feldick, A., and Modest, M., "Simulation of Hypersonic Flow and Radiation over a Mars Reentry Vehicle Using OpenFOAM," 50th AIAA Aerospace Sciences Meeting Including the New Horizons Forum and Aerospace Exposition, AIAA Paper 2012-0650, 2012.

[36] Chapuis, M., Fureby, C., Fedina, E., Alin, N., and Tegnér, J., "Les Modeling of Combustion Applications Using OpenFOAM," $V$ European Conference on Computational Fluid Dynamics, ECCOMAS CFD, Barcelona, 2010, pp. 14-17.

[37] Afarin, Y., Tabejamaat, S., and Mardani, A., "Large Eddy Simulation Study of $\mathrm{H}_{2} / \mathrm{CH}_{4}$ Flame Structure at MILD Condition," Seventh Mediterranean Combustion Symposium, Italian Sec. of the Combustion Inst., Naples, Italy, 2011.

[38] Hollis, B. R., "Real-Gas Flow Properties for NASA Langley Research Center Aerothermodynamic Facilities Complex Wind Tunnels," NASA Langley Research Center, Contractor Rept. 4755, 1996.

[39] NIST-JANAF Thermochemical Tables [online database], National Inst. of Standards and Technology, http://kinetics.nist.gov/janaf/ [retrieved 19 May 2011].

[40] Brodkey, R. S., and Hershey, H. C., Transport Phenomena: A Unified Approach, Brodkey Publ., Columbus, OH, 2003, p. 724.

[41] Neufeld, P. D., Janzen, A. R., and Aziz, R. A., "Empirical Equations to Calculate 16 of the Transport Collision Integrals $\Omega(1, s)^{*}$ for the Lennard-Jones (12-6) Potential," Journal of Chemical Physics, Vol. 57, No. 3, 2003, pp. 1100-1102. doi: $10.1063 / 1.1678363$

[42] Jiang, N., Webster, M., Lempert, W. R., Miller, J. D., Meyer, T. R., Ivey, C. B., and Danehy, P. M., "MHz-Rate Nitric Oxide Planar Laser-Induced Fluorescence Imaging in a Mach 10 Hypersonic Wind Tunnel," Applied Optics, Vol. 50, No. 4, 2011, pp. A20-A28. doi:10.1364/AO.50.000A20

[43] Bathel, B. F., Danehy, P. M., Inman, J. A., Jones, S., Ivey, C., and Goyne, C., "Multiple Velocity Profile Measurements in Hypersonic Flows
Using Sequentially-Imaged Fluorescence Tagging,” AIAA Paper 2010$1404,2010$.

[44] Jasak, H., Weller, H. G., and Gosman, A. D., "High Resolution NVD Differencing Scheme for Arbitrarily Unstructured Meshes," International Journal for Numerical Methods in Fluids, Vol. 31, No. 2, 1999, pp. 431-449. doi:10.1002/(ISSN)1097-0363

[45] Davenport, W. J., "Boundary Layer Applets" [online database], http:// www.engapplets.vt.edu/fluids/bls2 [retrieved 19 May 2011].

[46] Johansen, C., and Danehy, P., "Numerical Investigation of PLIF Gas Seeding for Hypersonic Boundary Layer Flows," 50th AIAA Aerospace Sciences Meeting Including the New Horizons Forum and Aerospace Exposition, AIAA Paper 2012-1057, 2012.

[47] Narayanaswamy, V., Burns, R., and Clemens, N. T., "Kr-PLIF for Scalar Imaging in Supersonic Flows," Optics Letters, Vol. 36, No. 21, Nov. 2011, Paper 4185. doi:10.1364/OL.36.004185

[48] Exton, R. J., Balla, R. J., Shirinzadeh, B., Hillard, M. E., and Brauckmann, G. J., "Flow Visualization Using Fluorescence from Locally Seeded $\mathrm{I}_{2}$ Excited by an ArF Excimer Laser," Experiments in Fluids, Vol. 26, No. 4, 1999, pp. 335-339. doi: $10.1007 / \mathrm{s} 003480050296$

[49] Hartfield, R. J., Jr., Abbitt, J. D., III, and McDaniel, J. C., "Injectant Mole-Fraction Imaging in Compressible Mixing Flows Using Planar Laser-Induced Iodine Fluorescence," Optics Letters, Vol. 14, No. 16, Aug. 1989 , pp. 850-852. doi:10.1364/OL.14.000850

[50] OSHA Occupational Chemical Database [online database], U.S. Dept. of Labor, Occupational Safety and Health Administration, https://www .osha.gov/chemicaldata/index.html [retrieved 8 Dec. 2011].

[51] Olbregts, J., "Termolecular Reaction of Nitrogen Monoxide and Oxygen: A Still Unsolved Problem," International Journal of Chemical Kinetics, Vol. 17, No. 8, 1985, pp. 835-848. doi:10.1002/(ISSN)1097-4601

L. Ukeiley Associate Editor 